\title{
Reaction in situ found in the synthesis of a series of lanthanide sulfate complexes and investigation on their structure, spectra and catalytic activity
}

\author{
Zhaoyan Deng ${ }^{1}$, Fengying Bai ${ }^{2}$, Yongheng Xing ${ }^{1 *}$, Na Xing ${ }^{1}$, Liting Xu ${ }^{1}$ \\ ${ }^{1}$ College of Chemistry and Chemical Engineering, Liaoning Normal University, Dalian, China \\ ${ }^{2}$ College of Life Science, Liaoning Normal University, Dalian, China \\ Email: ${ }^{*}$ hhxing2000@yahoo.com
}

Received 11 March 2013; revised 11 April 2013; accepted 18 April 2013

Copyright (C) 2013 Zhaoyan Deng et al. This is an open access article distributed under the Creative Commons Attribution License, which permits unrestricted use, distribution, and reproduction in any medium, provided the original work is properly cited.

\begin{abstract}
A series of lanthanide sulfates coordination complexes, $\mathrm{Ln}_{2}\left(\mathrm{SO}_{4}\right)_{3}\left(\mathrm{H}_{2} \mathrm{O}\right)_{8}(\mathrm{Ln}=\operatorname{Pr}(1)$, Nd (2), $\mathrm{Tb}$ (3), Sm (4), Dy (5), Gd (7), Ho (8)), and $\operatorname{EuK}\left(\mathrm{SO}_{4}\right)_{2}(6)$, were constructed by the reaction in situ of lanthanide ions $\left(\mathrm{Ln}^{3+}\right)$ with flexible dodecanedioic acid and rigid aromatic 5-sulfosalicylic acid under hydrothermal conditions. All of them were characterized by elemental analysis, IR spectroscopy, and single-crystal $\mathrm{X}$-ray diffraction. The crystal structures and coordination modes of metal centers and sulfate ions, as well as the novel reaction mechanism and different conditions of lanthanide ions and 5 -sulfosalicylic acid to form the series of lanthanide sulfate complexes, were discussed in detail. Solid-state properties for these crystalline materials, such as thermal stability and powder $X$-ray diffraction have been investigated. Additionally, the photoluminescent characterizations of the complexes 3, 4, 5 and 6 , and the catalytic properties of all the complexes about cyclohexane being oxidized into cyclohexanone/cyclohexanol were investigated and compared.
\end{abstract}

Keywords: Lanthanide Sulfates; Hydrothermal Synthesis; Crystal Structure; Photoluminescent Properties; Catalytic Reaction

\section{INTRODUCTION}

Metal-organic frameworks (MOFs) [1], as a relatively new class of crystalline coordination polymers, have in the past decades become one of the fastest growing fields in chemistry, which is due to the significance both in academia and industry not only for their structural varie-

${ }^{*}$ Corresponding author. ties but also for their fascinating potential applications as functional crystalline materials, including gas storage, carbon dioxide capture and renewable catalysts [2-10]. Compared with transition metal, lanthanide-organic frameworks (LMOFs) possess more unique advantages because of the better optics and magnetism characters from the lanthanide themselves and more coordination numbers which is due to the larger radii of the lanthanide atoms [11-16]. In addition, the selection and accommodation of ligands play a key role for the construction of LMOFs, and therefore, mixed organic ligands, particularly in rigid-flexible ligands, have been proven to be effective and useful to enrich the varieties of lanthanide-organic frameworks because of their specific features: 1) Rigid ligands play important roles in constructing a stable framework and enhance the fluorescence emissions of complexes; 2) The rotation of the flexible ligands increases the variety of configurations of the coordination polymers [17-33].

As we know, a great number of examples about lanthanide-organic framework with rigid aromatic multicarboxylate have been reported, such as benzoic acid [34,35], 1,2-benzene dicarboxylic acid $\left(o-\mathrm{H}_{2} \mathrm{BDC}\right)$ [36], 1,3-benzene dicarboxylic acid $\left(m-\mathrm{H}_{2} \mathrm{BDC}\right)$ [37,38], 1,4benzene dicarboxylic acid ( $\left.p-\mathrm{H}_{2} \mathrm{BDC}\right)[39,40]$, benzene-1,3,5-tricarboxylic acid $\left(\mathrm{H}_{3} \mathrm{BTC}\right)$ [41], and 1,2,4,5benzenetetracarboxylic acid $\left(\mathrm{H}_{4} \mathrm{BTEC}\right)[42,43]$. However, ligands with the interesting functional sulfonic group to construct lanthanide complexes have been rarely explored and only the complexes $\left[\mathrm{Eu}(p-\mathrm{Tos})\left(\mathrm{H}_{2} \mathrm{O}\right)_{7}\right][p-\mathrm{Tos}]_{2}$ $\left(\mathrm{H}_{2} \mathrm{O}\right)_{2}\left(p\right.$-Tos $=$ Toluene-4-sulfonate) $[44] ;\left[\operatorname{Ln}_{2}(\mathrm{ad})_{2.5}\right.$ $\left.(\mathrm{BSA})\left(\mathrm{H}_{2} \mathrm{O}\right)_{2}\right]_{\mathrm{n}}\left(\mathrm{Ln}=\mathrm{Sm}, \mathrm{Nd} ; \mathrm{H}_{2}\right.$ ad = adipic acid; $\mathrm{BAS}$ $=$ benzenesulfonate) [45]; $\left[\mathrm{Eu}(\mathrm{BSA})(\mathrm{glu})\left(\mathrm{H}_{2} \mathrm{O}\right)_{2}\right] \cdot \mathrm{H}_{2} \mathrm{O}$ $\left(\mathrm{Ln}=\mathrm{Eu}, \mathrm{Sm}, \mathrm{Ce}, \mathrm{Pr}, \mathrm{Nd} ; \mathrm{H}_{2}\right.$ glu = glutaric acid, $\mathrm{HBSA}=$ benzene sulfonic acid); $\mathrm{Ln}(\mathrm{SSA})\left(\mathrm{H}_{2} \mathrm{O}\right)_{2}(\mathrm{SSA}=5$-sulfosalicylic acid, $\mathrm{Ln}=\mathrm{Ce}, \mathrm{Pr}, \mathrm{Nd}$ and $\mathrm{Dy}$ ) [46]; and 
$\left[\mathrm{Ln}(\mathrm{SSA})\left(\mathrm{H}_{2} \mathrm{O}\right)_{2}\right]_{\mathrm{n}} \cdot \mathrm{nH}_{2} \mathrm{O}(\mathrm{SSA}=5$-sulfosalicylic acid, $\mathrm{Ln}=\mathrm{Gd}, \mathrm{Sm}, \mathrm{Nd}, \mathrm{Tb}, \mathrm{Eu}, \mathrm{Yb}$ and Dy) [47] appear in the present literatures. 5-sulfosalicylic acid, possessing three potential coordinating groups, $-\mathrm{COOH},-\mathrm{SO}_{3} \mathrm{H}$ and $-\mathrm{OH}$, can act as the preferential ligand of the lanthanide complexes [48-51]. In addition, although a number of the lanthanide complexes with flexible linkers have been reported, complexes with aliphatic diacid with more than ten carbon atoms have never been reported [52].

Therefore, in our previous work, we selected 5-sulfosalicylic acid and at the same time chose dodecanedioic acid in synthesizing the rigid-flexible lanthanide coordination polymers. Nevertheless, it is not predictable at all to receive the established products, but surprising that there exist two kinds of 2-D or 3-D lanthanide sulfates after the hydrothermal reaction when these two different acids and lanthanide chloride were dissolved in water/ethanol system, and the resultant reaction has never before been reported. Although there are a great number of reports on organic amine template complexes of the lanthanide sulfates, they generally used lanthanide sulfates as the starting material and employed a special organic amine as the structure-directing agent (SDA) or the $\mathrm{pH}$-adjusting agent [53-56]. Hence, one recognizes that organic amine was directly inserted into the structure of the product, and inevitably, as a result, it is hard to produce some single sulfato lanthanide complexes. Moreover, reports on a series of complexes of lanthanide sulfates are very few. Recently, we used a reaction in situ to synthesize a series of the sulfato lanthanide complexes, $\mathrm{Ln}_{2}\left(\mathrm{SO}_{4}\right)_{3}\left(\mathrm{H}_{2} \mathrm{O}\right)_{8}(\mathrm{Ln}=\operatorname{Pr}(\mathbf{1}), \mathrm{Nd}(\mathbf{2}), \mathrm{Tb}(\mathbf{3}), \mathrm{Sm}(\mathbf{4}), \mathrm{Dy}(\mathbf{5})$, $\mathrm{Gd}(\mathbf{7}), \mathrm{Ho}(\mathbf{8})$ ), $\mathrm{EuK}\left(\mathrm{SO}_{4}\right)_{2}(\mathbf{6})$ (shown in Scheme 1).

\section{EXPERIMENTAL SECTION}

\subsection{Materials and Methods}

All chemicals purchased were of reagent grade or better and were used without further purification. Lanthanide chloride salts were prepared via dissolving $10 \mathrm{~g}$ praseodymium oxides with $100 \mathrm{ml} 12 \mathrm{M} \mathrm{HCl}$ and then evaporating at $100^{\circ} \mathrm{C}$ until the crystal film formed. The infrared spectra were recorded on a JASCO FT/IR-480 PLUS Fourier Transform spectrometer with pressed $\mathrm{KBr}$ pellets in the range $400-4000 \mathrm{~cm}^{-1}$. The luminescence spectra were reported on F-7000 FL Spectrophotometer (200 $800 \mathrm{~nm}$ ). The elemental analyses were carried out on a Perkin Elmer 240C automatic analyzer. Lanthanide con-

$$
\begin{aligned}
\mathrm{Ln}^{3+}+\underset{\mathrm{NOOH}}{\mathrm{EtOH} / \mathrm{H}_{2} \mathrm{O}} \longrightarrow & \left\{\begin{array}{l}
\mathrm{EuK}\left(\mathrm{SO}_{4}\right)_{2}(6) \\
\mathrm{Ln}=\operatorname{Pr}(1), \mathrm{Nd}(2), \mathrm{Tb}(3), \mathrm{Sm}(4), \\
\operatorname{Ly}(5), \mathrm{Gd}(7), \mathrm{Ho}(8)
\end{array}\right.
\end{aligned}
$$

Scheme 1. Synthesis method of complexes $1-8$. tents were analyzed on a Plasma-Spec(I)-AES model ICP spectrometer. X-ray powder diffraction (XRD) data were collected on a Bruker Advance-D8 with $\mathrm{Cu}-\mathrm{Ka}$ radiation, in the range $5^{\circ}<2 \theta<60^{\circ}$, with a step size of $0.02^{\circ}(2 \theta)$ and an acquisition time of $2 \mathrm{~s}$ per step.

\subsection{Synthesis of the Complexes}

$\left[\mathrm{Pr}_{2}\left(\mathrm{SO}_{4}\right)_{3}\left(\mathrm{H}_{2} \mathrm{O}\right)_{8}\right]$ (1). Complexes 1 were prepared by hydrothermal reaction. In a typical synthesis, solution I was prepared by dissolving $\operatorname{PrCl}_{3} \cdot 6 \mathrm{H}_{2} \mathrm{O}(0.107 \mathrm{~g}, 0.3$ mmol) and 5-sulfosalicylic acid $(0.076 \mathrm{~g}, 0.30 \mathrm{mmol})$ into $5.0 \mathrm{ml}$ ethanol under stirring for $1-2 \mathrm{~h}$, dodecanedioic acid $(0.069 \mathrm{~g}, 0.3 \mathrm{mmol})$ was added to 5.0 $\mathrm{ml}$ ethanol to make solution II . $5.0 \mathrm{ml}$ deionized water was added after solution I was mixed with solution II under stirring for a minimum of 1-2 $\mathrm{h}$. Then, one drop of saturated $\mathrm{KOH}(\mathrm{aq})$ was added into the mixture solution under stirring. The final mixture was transferred to a 25 $\mathrm{ml}$ Teflon-lined stainless steel vessel under autogenous pressure and heated at $160^{\circ} \mathrm{C}$ for 3 days. Colorless single crystals of $\mathbf{1}$ for X-ray diffraction analysis were obtained in ca. $74 \%$ yield based on $\operatorname{Pr}(\mathrm{III})$ after two weeks. Elemental analysis for $\mathrm{H}_{16} \mathrm{O}_{20} \mathrm{~S}_{3} \operatorname{Pr}_{2}\left(M_{\mathrm{r}}=714.16\right)$, calcd: Pr, 39.46; H, 2.26\%. Found: $\operatorname{Pr}, 39.41 ; \mathrm{H}, 2.50 \%$. IR data (KBr pellet, $\left.v\left[\mathrm{~cm}^{-1}\right]\right): 3450.51(\mathrm{~s}), 2923.64(\mathrm{w}), 2855.35$ (w), $1637.26(\mathrm{~s}), 1123.90(\mathrm{~s}), 980.17(\mathrm{w}), 651.43(\mathrm{~m})$, $597.03(\mathrm{~m})$.

$\left[\mathrm{Nd}_{2}\left(\mathrm{SO}_{4}\right)_{3}\left(\mathrm{H}_{2} \mathrm{O}\right)_{8}\right]$ (2). This complex was synthesized by a procedure similar to that used for $\mathbf{1}$ but changing the $\mathrm{PrCl}_{3} \cdot 6 \mathrm{H}_{2} \mathrm{O}$ to $\mathrm{NdCl}_{3} \cdot 6 \mathrm{H}_{2} \mathrm{O}(0.108 \mathrm{~g}, 0.30 \mathrm{mmol})$, purple crystals of 2 were obtained in ca. $69 \%$ yield based on $\mathrm{Nd}$ (III). Elemental analysis for $\mathrm{H}_{16} \mathrm{O}_{20} \mathrm{~S}_{3} \mathrm{Nd}_{2}\left(M_{\mathrm{r}}=720.82\right)$ : Nd: 40.02; H, 2.24\%. Found: Nd: 40.00; H, 2.36\%. IR data $\left(\mathrm{KBr}\right.$ pellet, $\left.v\left[\mathrm{~cm}^{-1}\right]\right): 3423.01(\mathrm{~s}), 1642.38(\mathrm{~s})$, $1130.83(\mathrm{~s}), 998.28(\mathrm{w}), 658.03(\mathrm{~m}), 599.73(\mathrm{~m})$.

$\left[\mathrm{Tb}_{2}\left(\mathrm{SO}_{4}\right)_{3}\left(\mathrm{H}_{2} \mathrm{O}\right)_{8}\right](3)$. This complex was synthesized by a procedure similar to that used for $\mathbf{1}$ but changing the $\mathrm{PrCl}_{3} \cdot 6 \mathrm{H}_{2} \mathrm{O}$ to $\mathrm{TbCl}_{3} \cdot 6 \mathrm{H}_{2} \mathrm{O}(0.112 \mathrm{~g}, 0.30 \mathrm{mmol})$, colorless crystals of 3 were obtained in ca. 78\% yield based on $\mathrm{Tb}(\mathrm{III})$. Elemental Anal. Calc. for $\mathrm{H}_{16} \mathrm{O}_{20} \mathrm{~S}_{3} \mathrm{~Tb}_{2}(\mathrm{Mr}=$ 750.20): $\mathrm{Tb}, 42.37 ; \mathrm{H}, 2.15 \%$. Found: $\mathrm{Tb}, 42.31 ; \mathrm{H}$, $2.42 \%$. IR data $\left(\mathrm{KBr}\right.$ pellet, $\left.\mathrm{m}\left[\mathrm{cm}^{-1}\right]\right): 3487.70(\mathrm{~s})$, 3371.48 (s), 1642.38 (s), 1143.62 (s), 1092.09 (s), 1001.07 (m), 806.98 (w), 606.12 (s), 489.52 (s), 424.82 (w).

$\left[\mathrm{Sm}_{2}\left(\mathrm{SO}_{4}\right)_{3}\left(\mathrm{H}_{2} \mathrm{O}\right)_{8}\right]$ (4). This complex was synthesized by a procedure similar to that used for $\mathbf{1}$ but changing the $\mathrm{PrCl}_{3} \cdot 6 \mathrm{H}_{2} \mathrm{O}$ to $\mathrm{SmCl}_{3} \cdot 6 \mathrm{H}_{2} \mathrm{O}(0.109 \mathrm{~g}, 0.30 \mathrm{mmol})$, primrose yellow crystals of 4 were obtained in ca. $76 \%$ yield based on Sm (III). Elemental analysis for $\mathrm{H}_{16} \mathrm{O}_{20} \mathrm{~S}_{3} \mathrm{Sm}_{2}$ $\left(M_{\mathrm{r}}=733.06\right)$ : Sm, 41.02; H, 2.20\%. Found: Sm, 39.96; $\mathrm{H}, 2.51 \%$. IR data $\left(\mathrm{KBr}\right.$ pellet, $\left.v\left[\mathrm{~cm}^{-1}\right]\right): 3448.96(\mathrm{~s})$, 1642.38 (s), $1124.44(\mathrm{~s}), 1007.84(\mathrm{w}), 651.64(\mathrm{w})$, $599.73(\mathrm{~s}), 489.52(\mathrm{w})$. 
$\left[\mathrm{Dy}_{2}\left(\mathrm{SO}_{4}\right)_{3}\left(\mathrm{H}_{2} \mathrm{O}\right)_{8}\right](5)$. This complex was synthesized by a procedure similar to that used for $\mathbf{1}$ but changing the $\mathrm{PrCl}_{3} \cdot 6 \mathrm{H}_{2} \mathrm{O}$ to $\mathrm{DyCl}_{3} \cdot 6 \mathrm{H}_{2} \mathrm{O}(0.113 \mathrm{~g}, 0.30 \mathrm{mmol})$, colorless crystals of 5 were obtained in ca. $71 \%$ yield based on Dy (III). Elemental analysis for $\mathrm{H}_{16} \mathrm{O}_{20} \mathrm{~S}_{3} \mathrm{Dy}_{2}\left(M_{\mathrm{r}}=\right.$ 757.34): Dy, 42.91; H, 2.13\%. Found: Dy, 42.83; H, $2.16 \%$. IR data $\left(\mathrm{KBr}\right.$ pellet, $\left.v\left[\mathrm{~cm}^{-1}\right]\right): 3481.31(\mathrm{~s})$, 3371.48 (s), $3235.32(\mathrm{~m}), 1642.38(\mathrm{~s}), 1150.02(\mathrm{w})$, $1198.49(\mathrm{~s}), 1001.07(\mathrm{~s}), 813.37(\mathrm{~m}), 748.68(\mathrm{~m}), 690.38$ $(\mathrm{w}), 651.64(\mathrm{w}), 606.12(\mathrm{~s}), 489.52(\mathrm{~m}), 431.22(\mathrm{~m})$.

$\mathrm{EuK}\left(\mathrm{SO}_{4}\right)_{2}$ (6). This complex was synthesized by a procedure similar to that used for $\mathbf{1}$ but changing the $\mathrm{PrCl}_{3} \cdot 6 \mathrm{H}_{2} \mathrm{O}$ to $\mathrm{EuCl}_{3} \cdot 6 \mathrm{H}_{2} \mathrm{O}(0.110 \mathrm{~g}, 0.30 \mathrm{mmol})$, primrose yellow crystals of 6 were obtained in ca. $67 \%$ yield based on $\mathrm{Eu}$ (III). Elemental analysis for $\mathrm{EuK}\left(\mathrm{SO}_{4}\right)_{2}\left(M_{\mathrm{r}}\right.$ = 383.21): Eu, 39.66; K, 10.20\%. Found: Eu, 39.61; K, $10.12 \%$. IR data $\left(\mathrm{KBr}\right.$ pellet, $\left.v\left[\mathrm{~cm}^{-1}\right]\right): 3432.24(\mathrm{w})$, 2926.42 (w), 2857.74 (w), 1743.66 (w), 1265.24 (w), $1121.91(\mathrm{~s}), 636.34(\mathrm{~s}), 602.19(\mathrm{~s}), 451.72(\mathrm{w})$.

$\left[\mathrm{Gd}_{2}\left(\mathrm{SO}_{4}\right)_{3}\left(\mathrm{H}_{2} \mathrm{O}\right)_{8}\right]$ (7). This complex was synthesized by a procedure similar to that used for $\mathbf{1}$ but changing the $\mathrm{PrCl}_{3} \cdot 6 \mathrm{H}_{2} \mathrm{O}$ to $\mathrm{GdCl}_{3} \cdot 6 \mathrm{H}_{2} \mathrm{O}(0.111 \mathrm{~g}, 0.30 \mathrm{mmol})$, colorless crystals of 7 were obtained in ca. $66 \%$ yield based on $\mathrm{Gd}$ (III). Elemental analysis for $\mathrm{H}_{16} \mathrm{O}_{20} \mathrm{~S}_{3} \mathrm{Gd}_{2}\left(M_{\mathrm{r}}=\right.$ 746.84): Gd, 42.11\%; H, 2.16\%. Found: Gd, 42.06; H, $2.25 \%$. IR data $\left(\mathrm{KBr}\right.$ pellet, $\left.v\left[\mathrm{~cm}^{-1}\right]\right): 3481.31(\mathrm{~s})$, $3371.48(\mathrm{~s}), 3235.32(\mathrm{~m}), 1648.77$ (s), $1143.62(\mathrm{~s})$, 1092.09 (s), 1001.07 (s), 806.98 (w), 742.28 (w), 651.64 (w), $599.73(\mathrm{~s}), 489.52(\mathrm{~m}), 431.22(\mathrm{~m})$.

$\left[\mathrm{Ho}_{2}\left(\mathrm{SO}_{4}\right)_{3}\left(\mathrm{H}_{2} \mathrm{O}\right)_{8}\right](\mathbf{8})$. This complex was synthesized by a procedure similar to that used for $\mathbf{1}$ but changing the $\mathrm{PrCl}_{3} \cdot 6 \mathrm{H}_{2} \mathrm{O}$ to $\mathrm{HoCl}_{3} \cdot 6 \mathrm{H}_{2} \mathrm{O}(0.114 \mathrm{~g}, 0.30 \mathrm{mmol})$, pink crystals of 8 were obtained in ca. $61 \%$ yield based on Ho (III). Elemental analysis for $\mathrm{H}_{16} \mathrm{O}_{20} \mathrm{~S}_{3} \mathrm{Ho}_{2}\left(M_{\mathrm{r}}=762.20\right)$ : Ho, $43.28 \%$; H, 2.12\%. Found: Ho, 43.15\%; H, 2.32\%. IR data (KBr pellet, $\left.v\left[\mathrm{~cm}^{-1}\right]\right): 3486.64(\mathrm{~s}), 3384.20(\mathrm{~s})$, $3240.87(\mathrm{w}), 2331.67(\mathrm{w}), 1641.23(\mathrm{~s}), 1395.07(\mathrm{w})$, $1148.91(\mathrm{~s}), 1101.26(\mathrm{~s}), 1005.58(\mathrm{~s}), 608.94(\mathrm{~m}), 479.11$ (w), $438.22(\mathrm{w})$.

\subsection{Initial Characterization}

Initial characterizations were carried out by elemental analysis, PXRD and IR studies.

PXRD patterns were recorded in the $2 \theta$ range $5-50^{\circ}$ using $\mathrm{Cu}-\mathrm{K} \alpha$ radiation (Bruker Advance-D8), with a step size of $0.02^{\circ}(2 \theta)$ and a count time of $2 \mathrm{~s}$ per step. As shown in Figures S1-S8, all the peaks presented in the measured patterns closely match the simulated patterns generated from single crystal diffraction data, which confirm the phase purity of the bulk samples.

The IR spectra for the complexes were recorded as $\mathrm{KBr}$ pellets (Supporting Information, Figure S9 and S10). The IR spectra of complexes 1, 2, 3, 4, 5, 7 and 8 exhibit strong and broad absorption bands in the range of 3009 $-3679 \mathrm{~cm}^{-1}$ and $1640 \mathrm{~cm}^{-1}$, indicating the presence of coordination water moleculars. In 1, 2, 3, 4, 5, 7 and 8, the $\mathrm{SO}_{4}^{2-}$ ions adopt $\mu_{3}$ or $\mu_{2}$ coordination modes and lead to low site symmetry $\mathrm{C}_{3 \mathrm{v}}$ or $\mathrm{C}_{2 \mathrm{v}}$. The bands show medium strong intensity at 994 and $607 \mathrm{~cm}^{-1}$. These may be attributable to the symmetric S-O stretching mode $\left(v_{1}\right)$ and the symmetric $\mathrm{SO}_{4}^{2-}$ bending mode $\left(v_{2}\right)$. The strong band around $1117 \mathrm{~cm}^{-1}$ splitting into two bands, 1142 and $1093 \mathrm{~cm}^{-1}$, may be assigned to the $v_{3}$ mode because of the coordination of the free sulfate group to the metals. Compared with that of the above complexes, the IR spectra of complex 6 shows some difference in that there were only two main characteristic bands of $1139 \mathrm{~cm}^{-1}$ and $601 \mathrm{~cm}^{-1}$ ascribed to the vibration of the sulfate group [57-59].

\subsection{Single Crystal Structural Determinations}

A suitable single crystal of each compound was carefully selected under a cubic microscope and glued to a thin glass fiber for X-ray measurement. Of these reflection data of the complexes, 1-5, 7 and 8 were collected on a Bruker AXS SMART APEX II CCD diffractometer with graphite monochromatized Mo $\mathrm{K} \alpha$ radiation $(\lambda=$ $0.71073 \AA$ ), and that of 6 was collected on a Xcalibur, Atlas, Gemini ultra CCD diffractometer. The data were reduced using SAINTPLUS, and an empirical absorption correction was applied using the SADABS program. The structure was solved and refined using SHELXL-97. All the hydrogen positions were initially located in the different Fourier maps. Final refinement included atomic positions for all the atoms, anisotropic thermal parameters for all the non-hydrogen atoms, and isotropic thermal parameters for all the hydrogen atoms. Details of the structure solution and final refinements for the compounds are given in Tables $\mathbf{1}$ and 2 . The selected bond lengths and bond angles of complexes $\mathbf{3}$ are listed in Table 3, that of $\mathbf{6}$ are represented in Table 4, and that of $\mathbf{1}$, $2,4,5,7$ and 8 are shown in the supplement materials (Table S1-S6).

\subsection{Experiment Set up for Catalytic Oxidation}

The oxidation reactions were carried out under air condition (atmospheric pressure) in Schlenk tubes. In a typical experiment, $0.0004 \mathrm{~g}$ of the catalysts (complex 1-8) was dissolved in $3.00 \mathrm{ml}$ of desired solvent. Then the required amounts of $\mathrm{H}_{2} \mathrm{O}_{2}\left(30 \% \mathrm{H}_{2} \mathrm{O}_{2}\right.$ solution) and $\mathrm{HNO}_{3}$ were added according to this order. Finally, $0.68 \mathrm{~g}$ of cyclohexane was added into the solution to make the cyclohexane/catalyst molar ratio equal to 15,000 . The reaction solution was stirred for some time at the given temperature.

For the product analysis, $0.03 \mathrm{~g}$ of methylbenzene (internal standard) and $1.5 \mathrm{ml}$ of diethyl ether (to extract the substrate and the organic products from the reaction mixture) were added. The obtained mixture was stirred 
Table 1. Crystallographic data for complexes 1-4*.

\begin{tabular}{|c|c|c|c|c|}
\hline Complexes & 1 & 2 & 3 & 4 \\
\hline Empirical Formula & $\mathrm{H}_{16} \mathrm{O}_{20} \mathrm{Pr}_{2} \mathrm{~S}_{3}$ & $\mathrm{H}_{16} \mathrm{O}_{20} \mathrm{Nd}_{2} \mathrm{~S}_{3}$ & $\mathrm{H}_{16} \mathrm{O}_{20} \mathrm{~Tb}_{2} \mathrm{~S}_{3}$ & $\mathrm{H}_{16} \mathrm{O}_{20} \mathrm{Sm}_{2} \mathrm{~S}_{3}$ \\
\hline$M\left(\mathrm{~g} \cdot \mathrm{mol}^{-1}\right)$ & 714.13 & 720.79 & 750.15 & 733.01 \\
\hline Temperature( K) & 273(2) & $296(2)$ & $296(2)$ & $296(2)$ \\
\hline Crystal system & Monoclinic & Monoclinic & Monoclinic & Monoclinic \\
\hline Space group & $\mathrm{C} 2 / \mathrm{c}$ & $\mathrm{C} 2 / \mathrm{c}$ & $\mathrm{C} 2 / \mathrm{c}$ & $\mathrm{C} 2 / \mathrm{c}$ \\
\hline$a(\AA)$ & $13.7004(13)$ & $13.6617(8)$ & $13.5006(17)$ & $13.552(5)$ \\
\hline$b(\AA)$ & $6.8613(7)$ & $6.8366(4)$ & $6.7165(8)$ & $6.757(3)$ \\
\hline$c(\AA)$ & $18.4632(18)$ & $18.4353(12)$ & $18.247(2)$ & $18.272(7)$ \\
\hline$\alpha(\operatorname{deg})$ & 90 & 90 & 90 & 90 \\
\hline$\beta(\operatorname{deg})$ & $102.7970(10)$ & $102.6390(10)$ & $102.100(2)$ & $102.320(6)$ \\
\hline$\gamma(\operatorname{deg})$ & 90 & 90 & 90 & 90 \\
\hline$V\left(\AA^{3}\right)$ & $1692.5(3)$ & $1680.13(18)$ & $1617.8(3)$ & $1634.8(11)$ \\
\hline$Z$ & 4 & 4 & 4 & 4 \\
\hline$D_{\text {calc }}\left(\mathrm{g} \cdot \mathrm{cm}^{-3}\right)$ & 2.803 & 2.850 & 3.080 & 2.978 \\
\hline Crystal size (mm) & $0.17 \times 0.14 \times 0.09$ & $0.18 \times 0.14 \times 0.09$ & $0.18 \times 0.14 \times 0.09$ & $0.18 \times 0.14 \times 0.09$ \\
\hline $\mathrm{F}(000)$ & 1368 & 1376 & 1416 & 1392 \\
\hline$\mu(\mathrm{Mo}-\mathrm{K} \alpha) / \mathrm{mm}^{-1}$ & 6.158 & 6.584 & 9.162 & 7.599 \\
\hline$\theta(\operatorname{deg})$ & $2.26-24.97$ & $2.26-24.99$ & $2.28-28.43$ & $2.28-25.00$ \\
\hline Reflections collected & 4108 & 4034 & 4886 & 3914 \\
\hline Independent reflections & 1479 & 1473 & 1976 & 1423 \\
\hline $\mathrm{R}$ int & 0.0231 & 0.0249 & 0.0244 & 0.0231 \\
\hline Parameters & 122 & 123 & 130 & 131 \\
\hline$\Delta(\rho)\left(\right.$ e $\left.\AA^{-3}\right)$ & $0.633,-0.847$ & $0.889,-0.781$ & $0.776,-1.297$ & $1.012,-0.956$ \\
\hline Goodness of fit & 1.090 & 1.125 & 1.073 & 1.121 \\
\hline$R^{\mathrm{a}}$ & $0.0207(0.0228)^{\mathrm{b}}$ & $0.0209(0.0219)^{\mathrm{b}}$ & $0.0253(0.0311)^{\mathrm{b}}$ & $0.0180(0.0186)^{\mathrm{b}}$ \\
\hline $\mathrm{wR}_{2}{ }^{\mathrm{a}}$ & $0.0499(0.0509)^{\mathrm{b}}$ & $0.0550(0.0556)^{\mathrm{b}}$ & $0.0565(0.0590)^{\mathrm{b}}$ & $0.0448(0.0451)^{\mathrm{b}}$ \\
\hline
\end{tabular}

${ }^{*} \mathrm{R}=\Sigma|| \mathrm{Fo}|-| \mathrm{Fc}|| / \Sigma\left|\mathrm{Fo}_{\mathrm{o}}\right|, \mathrm{wR}_{2}=\left[\Sigma\left(\mathrm{w}\left(\mathrm{Fo}^{2}-\mathrm{Fc}^{2}\right)^{2} /\left[\Sigma\left(\mathrm{w}\left(\mathrm{Fo}^{2}\right)^{2}\right)^{1 / 2} ;[\mathrm{Fo}>4 \sigma(\mathrm{Fo})] .{ }^{\mathrm{b}} \mathrm{Based}\right.\right.\right.$ on all data.

for $10 \mathrm{~min}$ and then a sample $(0.8 \mu \mathrm{L})$ was taken from the organic phase and analyzed by a GC equipped with a capillary column and a flame ionization detector by the internal standard method. Blank experiments confirmed that no cyclohexanol or cyclohexanone were formed in the absence of the metal catalyst under the same conditions.

\section{RESULTS AND DISCUSSION}

\subsection{Synthesis}

As shown in Table 5, in the investigation we tried four methods in order to let the lanthanide ions coordinate with 5-sulfosalicylic acid and a flexible ligand, or to coordinate with 5-sulfosalicylic acid and another rigid ligand. The details are as follows. At first, we designed the experimental method (II), for the purpose of the coordination of lanthanide ions and 5-sulfosalicylic acid and chain-like aliphatic dicarboxylic acid to achieve novel complexes with 5-sulfosalicylic acid-dicarboxylic acid as rigid-flexible ligands. But unfortunately, every experimental result demonstrated that lanthanide ions only coordinated with aliphatic dicarboxylic acid. In this case, in order to explore the experimental conditions of the coordination of 5-sulfosalicylic acid and lanthanide 
Table 2. Crystallographic data for complexes 5-8*

\begin{tabular}{|c|c|c|c|c|}
\hline Complexes & 5 & 6 & 7 & 8 \\
\hline Empirical Formula & $\mathrm{H}_{16} \mathrm{O}_{20} \mathrm{Dy}_{2} \mathrm{~S}_{3}$ & $\mathrm{O}_{8} \mathrm{KEuS}$ & $\mathrm{H}_{16} \mathrm{O}_{20} \mathrm{Gd}_{2} \mathrm{~S}_{3}$ & $\mathrm{H}_{16} \mathrm{O}_{20} \mathrm{Ho}_{2} \mathrm{~S}_{3}$ \\
\hline$M\left(\mathrm{~g} \cdot \mathrm{mol}^{-1}\right)$ & 757.34 & 383.20 & 746.81 & 762.20 \\
\hline Temperature( K) & $296(2)$ & 293(2) & $296(2)$ & $296(2)$ \\
\hline Crystal system & Monoclinic & Triclinic & Monoclinic & Monoclinic \\
\hline Space group & $\mathrm{C} 2 / \mathrm{c}$ & $\mathrm{P} 1$ & $\mathrm{C} 2 / \mathrm{c}$ & $\mathrm{C} 2 / \mathrm{c}$ \\
\hline$a(\AA)$ & $13.5034(15)$ & $5.3589(3)$ & $13.574(2)$ & $13.4516(17)$ \\
\hline$b(\AA)$ & $6.7192(7)$ & $6.8831(6)$ & $6.7622(12)$ & $6.6885(8)$ \\
\hline$c(\AA)$ & $18.253(2)$ & $8.9525(11)$ & $18.337(3)$ & $18.171(2)$ \\
\hline$\alpha(\mathrm{deg})$ & 90 & $97.419(9)$ & 90 & 90 \\
\hline$\beta(\operatorname{deg})$ & $102.049(2)$ & $92.338(7)$ & $102.173(2)$ & $102.000(2)$ \\
\hline$\gamma(\operatorname{deg})$ & 90 & $91.025(6)$ & 90 & 90 \\
\hline $\mathrm{V}\left(\AA^{3}\right)$ & $1619.6(3)$ & $327.09(5)$ & $1645.3(5)$ & 1599.1(3) \\
\hline$Z$ & 4 & 2 & 4 & 4 \\
\hline$D_{\text {calc }}\left(\mathrm{g} \cdot \mathrm{cm}^{-3}\right)$ & 3.106 & 3.891 & 3.015 & 3.166 \\
\hline Crystal size (mm) & $0.18 \times 0.14 \times 0.09$ & $0.13 \times 0.10 \times 0.09$ & $0.18 \times 0.14 \times 0.09$ & $0.18 \times 0.14 \times 0.09$ \\
\hline $\mathrm{F}(000)$ & 1424 & 356 & 1408 & 1432 \\
\hline$\mu(\mathrm{Mo}-\mathrm{K} \alpha) / \mathrm{mm}^{-1}$ & 9.646 & 10.868 & 8.474 & 10.320 \\
\hline$\theta(\operatorname{deg})$ & $3.09-24.99$ & $2.99-24.99$ & $3.38-25.00$ & $2.29-28.47$ \\
\hline Reflections collected & 3792 & 2042 & 3814 & 4543 \\
\hline Independent reflections & 1408 & 1158 & 1430 & 1910 \\
\hline $\mathrm{R}$ int & 0.0392 & 0.0382 & 0.0324 & 0.0458 \\
\hline Parameters & 115 & 109 & 123 & 115 \\
\hline$\Delta(\rho)\left(\mathrm{e} \AA^{-3}\right)$ & $5.885,-6.613$ & $6.535,-1.757$ & $2.758,-2.049$ & $7.564,-6.235$ \\
\hline Goodness of fit & 1.258 & 1.052 & 1.150 & 1.180 \\
\hline$R^{\mathrm{a}}$ & $\begin{array}{c}0.0477 \\
(0.0478)^{b}\end{array}$ & $\begin{array}{c}0.0511 \\
(0.0535)^{b}\end{array}$ & $\begin{array}{c}0.0384 \\
(0.0397)^{b}\end{array}$ & $\begin{array}{c}0.0584 \\
(0.0589)^{\mathrm{b}}\end{array}$ \\
\hline $\mathrm{wR}_{2}{ }^{\mathrm{a}}$ & $\begin{array}{c}0.1077 \\
(0.1078)^{\mathrm{b}}\end{array}$ & $\begin{array}{c}0.1351 \\
(0.1379)^{\mathrm{b}}\end{array}$ & $\begin{array}{c}0.1101 \\
(0.1113)^{b}\end{array}$ & $\begin{array}{c}0.1413 \\
(0.1420)^{\mathrm{b}}\end{array}$ \\
\hline
\end{tabular}

${ }^{{ }^{a} \mathrm{R}} \mathrm{R}=\Sigma|| \mathrm{Fo}|-| \mathrm{Fc}|| / \Sigma|\mathrm{Fo}|, \mathrm{wR}_{2}=\left[\Sigma\left(\mathrm{w}\left(\mathrm{Fo}^{2}-\mathrm{Fc}^{2}\right)^{2} /\left[\Sigma\left(\mathrm{w}\left(\mathrm{Fo}^{2}\right)^{2}\right)^{1 / 2} ;[\mathrm{Fo}>4 \sigma(\mathrm{Fo})] .{ }^{\mathrm{b}}\right.\right.\right.$ Based on all data.

ions, the experiment of (I) was devised. That is, there were only the lanthanide chloride and 5-sulfasalicylic acid in the reaction systems. However, after the normal hydrothermal reaction and cooling, there was still only the clear solution and no desired crystal of the complexes, which lead us to reach a conclusion that 5-sulfosalicylic acid and lanthanide chloride could not directly react with each other in this condition. Then, we designed the experiments of (III) and (IV), that is, the weak acid of dodecanedioic acid or the weak base of 2,4,6-tis (3,5-dimethyl-1H-pyrazol-1-yl)-1,3,5-triazine were added in addition to the lanthanide ions and 5-sulfosalicylic acid because neither dodecanedioic acid nor 2,4,6-tis(3,5dimethyl-1H-pyrazol-1-yl)-1,3,5-triazine can easily coordinate with lanthanide ions in this reaction condition. Although lanthanide-3pz-CQ has been reported in the past literature, a lanthanide-dodecanedioic acid complex has never been reported. For 3pz-CQ compound, it is possible that lanthanide ions tend to coordinate with oxygen atoms, and coordinate with nitrogen only in an appropriately polar non-aqueous solvent such as ethanol. For dodecanedioic acid, since it possesses a too long 
Table 3. Selected bond distances $(\AA)$ and angles (deg) of complex 3 .

\begin{tabular}{|c|c|c|c|c|c|}
\hline \multicolumn{6}{|c|}{ Bond distances } \\
\hline $\mathrm{Tb}-\mathrm{O}(5)$ & $2.253(8)$ & $\mathrm{Tb}-\mathrm{O}(2)$ & $2.316(8)$ & $\mathrm{Tb}-\mathrm{O}(6)$ & $2.317(9)$ \\
\hline $\mathrm{Tb}-\mathrm{O}(4)$ & $2.326(9)$ & $\mathrm{Tb}-\mathrm{O}(1)$ & $2.366(9)$ & $\mathrm{Tb}-\mathrm{O}(8)$ & $2.429(8)$ \\
\hline $\mathrm{Tb}-\mathrm{O}(3)$ & $2.438(10)$ & $\mathrm{Tb}-\mathrm{O}(7)$ & $2.487(9)$ & & \\
\hline \multicolumn{6}{|c|}{ Bond angles } \\
\hline $\mathrm{O}(5)-\mathrm{Tb}-\mathrm{O}(2)$ & $143.0(3)$ & $\mathrm{O}(5)-\mathrm{Tb}-\mathrm{O}(6)$ & $80.4(3)$ & $\mathrm{O}(2)-\mathrm{Tb}-\mathrm{O}(6)$ & $126.1(3)$ \\
\hline $\mathrm{O}(5)-\mathrm{Tb}-\mathrm{O}(4)$ & $88.3(3)$ & $\mathrm{O}(2)-\mathrm{Tb}-\mathrm{O}(4)$ & $79.2(3)$ & $\mathrm{O}(6)-\mathrm{Tb}-\mathrm{O}(4)$ & $70.8(3)$ \\
\hline $\mathrm{O}(5)-\mathrm{Tb}-\mathrm{O}(1)$ & $147.2(3)$ & $\mathrm{O}(2)-\mathrm{Tb}-\mathrm{O}(1)$ & $69.2(3)$ & $\mathrm{O}(6)-\mathrm{Tb}-\mathrm{O}(1)$ & $79.7(3)$ \\
\hline $\mathrm{O}(4)-\mathrm{Tb}-\mathrm{O}(1)$ & 109.1(4) & $\mathrm{O}(5)-\mathrm{Tb}-\mathrm{O}(8)$ & $99.5(3)$ & $\mathrm{O}(2)-\mathrm{Tb}-\mathrm{O}(8)$ & $75.8(3)$ \\
\hline $\mathrm{O}(6)-\mathrm{Tb}-\mathrm{O}(8)$ & $141.3(3)$ & $\mathrm{O}(4)-\mathrm{Tb}-\mathrm{O}(8)$ & $147.7(3)$ & $\mathrm{O}(1)-\mathrm{Tb}-\mathrm{O}(8)$ & $80.6(3)$ \\
\hline $\mathrm{O}(5)-\mathrm{Tb}-\mathrm{O}(3)$ & $69.9(3)$ & $\mathrm{O}(2)-\mathrm{Tb}-\mathrm{O}(3)$ & $73.2(3)$ & $\mathrm{O}(6)-\mathrm{Tb}-\mathrm{O}(3)$ & $134.4(3)$ \\
\hline $\mathrm{O}(4)-\mathrm{Tb}-\mathrm{O}(3)$ & $74.4(3)$ & $\mathrm{O}(1)-\mathrm{Tb}-\mathrm{O}(3)$ & $140.6(3)$ & $\mathrm{O}(8)-\mathrm{Tb}-\mathrm{O}(3)$ & $78.9(3)$ \\
\hline $\mathrm{O}(5)-\mathrm{Tb}-\mathrm{O}(7)$ & $73.4(3)$ & $\mathrm{O}(2)-\mathrm{Tb}-\mathrm{O}(7)$ & $133.4(3)$ & $\mathrm{O}(6)-\mathrm{Tb}-\mathrm{O}(7)$ & $74.8(3)$ \\
\hline $\mathrm{O}(4)-\mathrm{Tb}-\mathrm{O}(7)$ & $143.2(3)$ & $\mathrm{O}(1)-\mathrm{Tb}-\mathrm{O}(7)$ & 76.4(3) & $\mathrm{O}(8)-\mathrm{Tb}-\mathrm{O}(7)$ & 68.4(3) \\
\hline $\mathrm{O}(3)-\mathrm{Tb}-\mathrm{O}(7)$ & $125.0(3)$ & & & & \\
\hline
\end{tabular}

Table 4. Selected bond distances $(\AA)$ and angles (deg) of complex $6^{*}$.

\begin{tabular}{|c|c|c|c|c|c|}
\hline \multicolumn{6}{|c|}{ Bond distances } \\
\hline $\mathrm{Eu}-\mathrm{O}(4)$ & $2.325(8)$ & $\mathrm{Eu}-\mathrm{O}(7) \# 1$ & $2.330(8)$ & $\mathrm{Eu}-\mathrm{O}(8) \# 2$ & $2.377(8)$ \\
\hline $\mathrm{Eu}-\mathrm{O}(3)$ & $2.438(7)$ & $\mathrm{Eu}-\mathrm{O}(5)$ & 2.443(9) & $\mathrm{Eu}-\mathrm{O}(1)$ & $2.445(8)$ \\
\hline $\mathrm{Eu}-\mathrm{O}(6) \# 3$ & $2.469(7)$ & $\mathrm{Eu}-\mathrm{O}(2)$ & $2.566(8)$ & $\mathrm{O}(6)-\mathrm{Eu} \# 6$ & $2.469(7)$ \\
\hline $\mathrm{O}(7)-\mathrm{Eu} \# 1$ & $2.330(8)$ & $\mathrm{O}(8)-\mathrm{Eu} \# 2$ & $2.377(8)$ & & \\
\hline \multicolumn{6}{|c|}{ Bond angles } \\
\hline $\mathrm{O}(4)-\mathrm{Eu}-\mathrm{O}(7) \# 1$ & $83.7(3)$ & $\mathrm{O}(4)-\mathrm{Eu}-\mathrm{O}(8) \# 2$ & $79.3(3)$ & $\mathrm{O}(7) \# 1-\mathrm{Eu}-\mathrm{O}(8) \# 2$ & $82.9(3)$ \\
\hline $\mathrm{O}(4)-\mathrm{Eu}-\mathrm{O}(3)$ & $121.0(3)$ & $\mathrm{O}(7) \# 1-\mathrm{Eu}-\mathrm{O}(3)$ & $78.6(3)$ & $\mathrm{O}(8) \# 2-\mathrm{Eu}-\mathrm{O}(3)$ & $150.3(3)$ \\
\hline $\mathrm{O}(4)-\mathrm{Eu}-\mathrm{O}(5)$ & $70.5(3)$ & $\mathrm{O}(7) \# 1-\mathrm{Eu}-\mathrm{O}(5)$ & $121.9(3)$ & $\mathrm{O}(8) \# 2-\mathrm{Eu}-\mathrm{O}(5)$ & $137.1(3)$ \\
\hline $\mathrm{O}(3)-\mathrm{Eu}-\mathrm{O}(5)$ & $72.7(3)$ & $\mathrm{O}(4)-\mathrm{Eu}-\mathrm{O}(1)$ & $136.4(3)$ & $\mathrm{O}(7) \# 1-\mathrm{Eu}-\mathrm{O}(1)$ & $139.5(3)$ \\
\hline $\mathrm{O}(8) \# 2-\mathrm{Eu}-\mathrm{O}(1)$ & $106.5(3)$ & $\mathrm{O}(3)-\mathrm{Eu}-\mathrm{O}(1)$ & $74.8(3)$ & $\mathrm{O}(5)-\mathrm{Eu}-\mathrm{O}(1)$ & $78.0(3)$ \\
\hline $\mathrm{O}(4)-\mathrm{Eu}-\mathrm{O}(6) \# 3$ & $149.2(3)$ & $\mathrm{O}(7) \# 1-\mathrm{Eu}-\mathrm{O}(6) \# 3$ & $74.0(3)$ & $\mathrm{O}(8) \# 2-\mathrm{Eu}-\mathrm{O}(6) \# 3$ & $77.1(3)$ \\
\hline $\mathrm{O}(3)-\mathrm{Eu}-\mathrm{O}(6) \# 3$ & $75.6(2)$ & $\mathrm{O}(5)-\mathrm{Eu}-\mathrm{O}(6) \# 3$ & $139.7(3)$ & $\mathrm{O}(1)-\mathrm{Eu}-\mathrm{O}(6) \# 3$ & $70.2(3)$ \\
\hline $\mathrm{O}(4)-\mathrm{Eu}-\mathrm{O}(2)$ & $85.3(3)$ & $\mathrm{O}(7) \# 1-\mathrm{Eu}-\mathrm{O}(2)$ & $158.8(3)$ & $\mathrm{O}(8) \# 2-\mathrm{Eu}-\mathrm{O}(2)$ & $77.4(3)$ \\
\hline $\mathrm{O}(3)-\mathrm{Eu}-\mathrm{O}(2)$ & $122.6(3)$ & $\mathrm{O}(5)-\mathrm{Eu}-\mathrm{O}(2)$ & $70.6(3)$ & $\mathrm{O}(1)-\mathrm{Eu}-\mathrm{O}(2)$ & $55.6(2)$ \\
\hline $\mathrm{O}(6) \# 3-\mathrm{Eu}-\mathrm{O}(2)$ & $108.3(3)$ & & & & \\
\hline
\end{tabular}

*Symmetry transformations used to generate equivalent atoms: $\# 1-x+2,-y,-z+2 \# 2-x+1,-y,-z+2 \# 3 x, y+1, z \# 6 x, y-1, z$.

carbon chain and large steric hindrance, it maybe not coordinate with lanthanide ions to form stable skeleton of complexes. According to the experimental case above, we can use their insolubility and inertia of coordination with lanthanide ions to promote the coordination of lanthanide ions and 5-sulfosalicylic acid. Based on these points, we chose the mixed solvents of water-ethanol. On one hand, it makes the inert ligand dissolve well in the 
Table 5. Experimental strategies demonstrating the reaction mechanism.

\begin{tabular}{|c|c|c|c|c|c|}
\hline Methods & & & aterials & Conditions & Products \\
\hline ( I ) & $\mathrm{LnCl}_{3} \cdot 6 \mathrm{H}_{2} \mathrm{O}$ & $\mathrm{H}_{3} \mathrm{SSA}$ & & Hydrothermal $\left(160^{\circ} \mathrm{C}, \mathrm{H}_{2} \mathrm{O} / \mathrm{EtOH}\right)$ & Solution (No crystal ) \\
\hline (II) & $\mathrm{LnCl}_{3} \cdot 6 \mathrm{H}_{2} \mathrm{O}$ & $\mathrm{H}_{3} \mathrm{SSA}$ & $\mathrm{HOOC}\left(\mathrm{CH}_{2}\right)_{\mathrm{n}} \mathrm{COOH}(0 \leq \mathrm{n} \geq 3)$ & Hydrothermal $\left(160^{\circ} \mathrm{C}, \mathrm{H}_{2} \mathrm{O} / \mathrm{EtOH}\right)$ & Ln-dicarboxylate complexes \\
\hline (III) & $\mathrm{LnCl}_{3} \cdot 6 \mathrm{H}_{2} \mathrm{O}$ & $\mathrm{H}_{3} \mathrm{SSA}$ & $\mathrm{HOOC}\left(\mathrm{CH}_{2}\right)_{\mathrm{n}} \mathrm{COOH}(10 \leq \mathrm{n} \geq 12)$ & Hydrothermal $\left(160^{\circ} \mathrm{C}, \mathrm{H}_{2} \mathrm{O} / \mathrm{EtOH}\right)$ & $\mathrm{Ln}-\mathrm{SO}_{4}$ complexes \\
\hline (IV) & $\mathrm{LnCl}_{3} \cdot 6 \mathrm{H}_{2} \mathrm{O}$ & $\mathrm{H}_{3} \mathrm{SSA}$ & 3Pz-CQ & Hydrothermal $\left(160^{\circ} \mathrm{C}, \mathrm{H}_{2} \mathrm{O} / \mathrm{EtOH}\right)$ & $\mathrm{Ln}(\mathrm{SSA})_{3}\left(\mathrm{H}_{2} \mathrm{O}\right)_{1.5}$ complex \\
\hline
\end{tabular}

*H3SSA: 5-sulfosalicylic acid. 3Pz-CQ: 2,4,6-tis(3,5-dimethyl-1H-pyrazol-1-yl)-1,3,5-triazine.

ethanol and strengthen the possibility of coordination with lanthanide ions. On the other hand, because of the addition of ethanol, it increases the mole concentration of 5 -sulfosalicylic acid which easily dissolves in water, and as a result, enhances the molecular collision possibilities and coordination opportunities of 5 -sulfosalicylic acid and lanthanide ions. All these promote the lanthanide ions to coordinate with the inert ligand as well as 5 -sulfosalicylic acid. But in fact, the results of the experiment of (III) indicated that when a weak acidic ligand was added in the reaction system a decomposition reaction of 5-sulfosalicylic acid occurred, and at the same time, it gave rise to a new reaction in situ, namely, the decomposed product $\left(\mathrm{SO}_{4}^{2-}\right)$ coordinated to lanthanide directly. This shows that in the reaction above both dodecanedioic acid and 2,4,6-tis(3,5-dimethyl-1H-pyrazol-1-yl)-1,3,5-triazine played a certain role as a $\mathrm{pH}$ adjusting agent and a structure-directing agent for the coordination of 5-sulfosalicylic acid and lanthanide ions. Compared to 2,4,6-tis(3,5-dimethyl-1H-pyrazol-1-yl)-1,3, 5 -triazine, it seems that dodecanedioic acid played a more important role for coordination. It might offer some protons for the system to be acidic. Then these protons attached at the juncture of the sulfo-group and phenyl and made the unstable 5-sulfosalicylic to decompose and form the rather stable salicylic acid, and the sulfo-group, which has fallen off from the phenyls, then coordinated with lanthanide ions. The detailed reaction mechanism was speculated in Scheme 2.

\subsection{Structural Description of Complexes}

$\mathrm{X}$-ray diffraction determination results reveal that coordination polymers $1-5,7,8$ are isomorphous, therefore complexes 3 and 6 are taken as the examples to present and describe the structures in detail.

Structure of $\mathrm{Ln}_{2}\left(\mathrm{SO}_{4}\right)_{3}\left(\mathrm{H}_{2} \mathrm{O}\right)_{8}, \quad(\mathrm{Ln}=\operatorname{Pr}(\mathbf{1}), \mathrm{Nd}(\mathbf{2})$, $\mathrm{Tb}(3), \operatorname{Sm}(4), \operatorname{Dy}(5), \operatorname{Gd}(\mathbf{7}), \operatorname{Ho}(\mathbf{8}))$

The structure of $\mathbf{3}$ reveals that it is a 2-D framework complex. The asymmetric unit of 3 contains one $\mathrm{Tb}^{3+}$ atom, one and a half $\mathrm{SO}_{4}^{2-}$ anions and four coordination water molecules. The $\mathrm{Tb}$ atom is eight-coordinated to

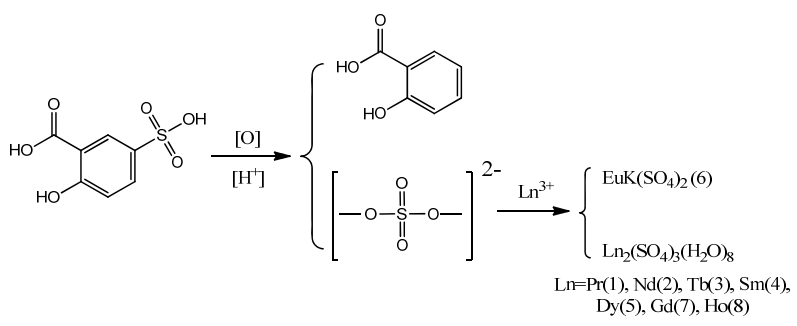

Scheme 2. Reaction mechanism of complexes 1-8.

four sulfate ions in the monodentate fashion and four water molecules (Figure 1(a), Figures S11(a)-S16(a)). Of the two framework sulfate ions, one binds to two $\mathrm{Tb}$ atoms in a monodentate fashion leaving two terminal $\mathrm{S}-\mathrm{O}$ bonds, whereas another binds to three metal atoms in a monodentate manner leaving one terminal $\mathrm{S}-\mathrm{O}$ bond (Scheme 3(d) and (c)). The linkage of the $\mathrm{TbO}_{8}$ polyhedra and the $\mathrm{SO}_{4}$ tetrahedra by sharing vertices gives rise to neutral inorganic layers parallel to the bc-plane, containing four-membered and eight-membered rings (Figure 1(b)), (Figures S11(b)-S16(b)).

$\mathrm{SO}_{4}^{2-}$ can be regarded as 2-connected and 3-connected linkers, and $\mathrm{Tb}^{3+}$ is surrounded by four $\mathrm{SO}_{4}^{2-}$ ligands and can be regarded as a 4-connected node. Topology analysis by the TOPOS 4.0 software package suggests that complex 3 possesses a 2D $(2,3,4)$-connected 3nodal network with a Schläfli symbol of $\left(4^{2} \cdot 6 \cdot 8^{2} \cdot 10\right)_{2}$ $\left(4^{2} .6\right)_{2}(8)$ (Figure 1(c), Figures S11(c)-S16(c)).

In the complex $\mathrm{Tb}_{2}\left(\mathrm{SO}_{4}\right)_{3}\left(\mathrm{H}_{2} \mathrm{O}\right)_{8}$, there exists seven kinds of intermolecular hydrogen bonding interactions of O1-H1A $\cdot$ O9, O1-H1B $\cdot$ O10, O3-H3A $\cdot$ O 7 , O3-H3B $\cdot \mathrm{O} 8, \mathrm{O} 4-\mathrm{H} 4 \mathrm{~A} \cdot \cdot \mathrm{O} 9, \mathrm{O} 4-\mathrm{H} 4 \mathrm{~B} \cdot \mathrm{O} 10$, $\mathrm{O} 7-\mathrm{H} 7 \mathrm{~B} \cdot \mathrm{O} 8$, in which they are respectively formed by water molecular and $\mathrm{SO}_{4}^{2-}$ ligands, except

$\mathrm{O} 3-\mathrm{H} 3 \mathrm{~A} \cdot \mathrm{O} 7$ which is formed by water molecules. In addition, O1-H1A.・O9, O4-H4A $\cdot \mathrm{O} 9$, O4-H4B $\cdot \mathrm{O} 10$ and O7-H7B $\cdot$ O8 linked the adjacent bc planes to generate a 3D framework. At the same time,

$\mathrm{O} 1-\mathrm{H} 1 \mathrm{~B} \cdot{ }^{\circ} \mathrm{O} 10, \mathrm{O} 3-\mathrm{H} 3 \mathrm{~A} \cdot \mathrm{O} 7, \mathrm{O} 3-\mathrm{H} 3 \mathrm{~B} \cdot \mathrm{O} 8$, as the intermolecular hydrogen bondings, further strengthen the whole structure of complexes (Figure 1(d), Figures S11(d)-S16(d)). As shown in Table 6, the hydrogen 


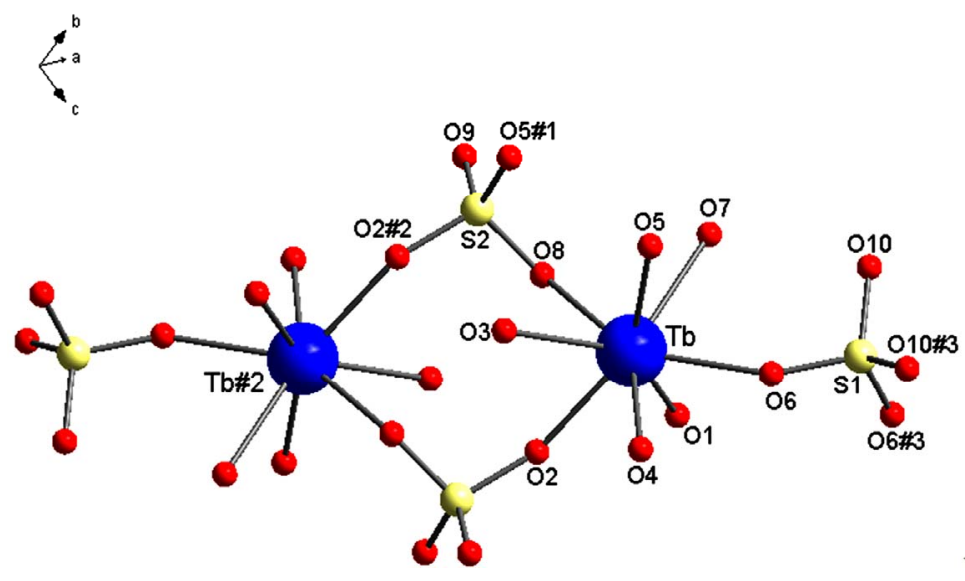

(a)

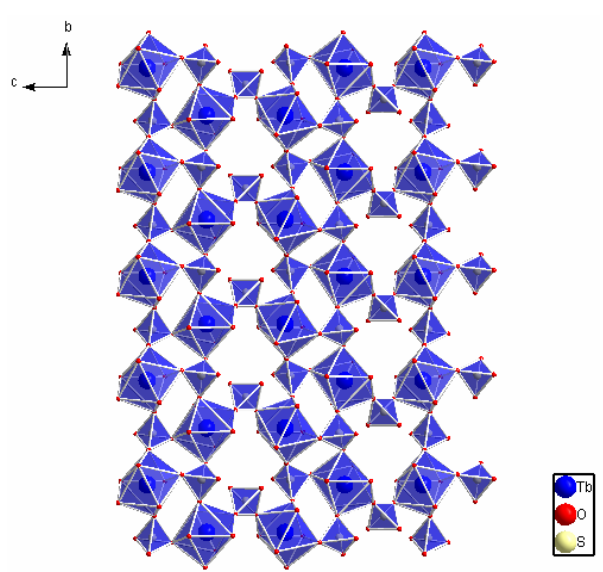

(b)

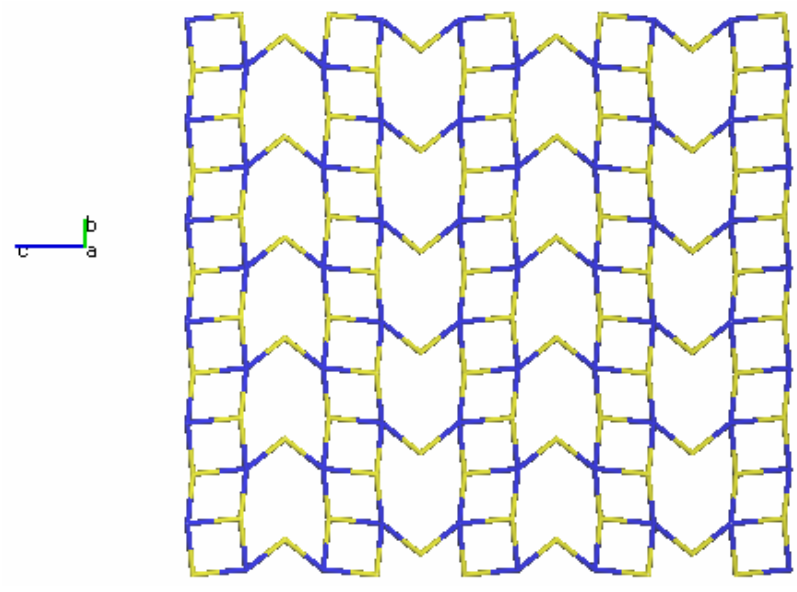

(c)

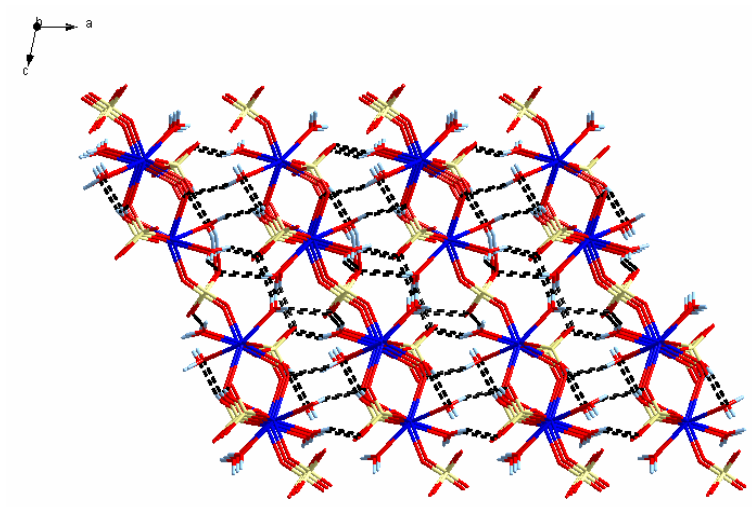

(d)

Figure 1. (a) The coordination environment of Tb in complex 7; (Symmetry codes: $\# 1$ : $-x+3 / 2,-y-1 / 2,-z+1$; \#2: $-x+3 / 2,-y+$ $1 / 2,-z+1 ; \# 3:-x+2, y,-z+3 / 2$ ); (b) The 2D layer in complex 3, viewed along the a-axis (c) Schematic representation of the 2D $\left(4^{2} .6 .8^{2} .10\right)_{2}\left(4^{2} .6\right)_{2}(8)$ topology network in complex 3. Blue, Tb; Yellow, $\mathrm{SO}_{4}^{2-}$. (d) A view of the 3D hydrogen bonding network structure of complex 3 (black dotted lines representing hydrogen bonding).

Table 6. Hydrogen bonds distances $(\AA)$ and angles $\left(^{\circ}\right)$ of complex $3^{*}$.

\begin{tabular}{ccccc}
\hline $\mathrm{D}-\mathrm{H} \cdots \mathrm{A}$ & $\mathrm{D}-\mathrm{H}$ & $\mathrm{H} \cdots \mathrm{A}$ & $\mathrm{D} \cdots \mathrm{A}$ & $<\mathrm{D}-\mathrm{H} \cdots \mathrm{A}$ \\
\hline $\mathrm{O} 1-\mathrm{H} 1 \mathrm{~A} \cdots \mathrm{O}^{\mathrm{g}}$ & 0.9000 & 1.8777 & 2.7151 & 153.93 \\
$\mathrm{O} 1-\mathrm{H} 1 \mathrm{~B} \cdots \mathrm{O} 10^{\mathrm{b}}$ & 0.9000 & 1.9754 & 2.8213 & 155.95 \\
$\mathrm{O} 3-\mathrm{H} 3 \mathrm{~A} \cdots 7^{\mathrm{e}}$ & 0.7911 & 2.1652 & 2.9413 & 166.93 \\
$\mathrm{O} 1-\mathrm{H} 3 \mathrm{~B} \cdots \mathrm{O}^{\mathrm{d}}$ & 0.7423 & 2.1431 & 2.7885 & 145.81 \\
$\mathrm{O} 4-\mathrm{H} 4 \mathrm{~A} \cdots \mathrm{O}^{\mathrm{h}}$ & 0.8999 & 2.1300 & 2.7584 & 126.16 \\
$\mathrm{O} 4-\mathrm{H} 4 \mathrm{~B} \cdots \mathrm{O} 10^{\mathrm{i}}$ & 0.9000 & 2.2402 & 2.8019 & 120.09 \\
$\mathrm{O} 7-\mathrm{H} 7 \mathrm{~B} \cdots \mathrm{O}^{\mathrm{k}}$ & 0.9044 & 2.1543 & 3.0366 & 164.89 \\
\hline
\end{tabular}

*Symmetry codes: g: 1/2+x, -1/2+y, z; b: x, $1+y, z ;$ : $1 / 2-x, 1 / 2-y,-z ; d: 1 / 2-x, 3 / 2-y,-z ; ~ h: 1 / 2-x,-1 / 2+y, 1 / 2-z ; i:-1 / 2+x, 1 / 2+y, z ; k: 1-x, 1+y$, $1 / 2-\mathrm{z}$.

bonding distances of $\mathrm{D} \cdots \mathrm{A}$ vary from 2.7151 to 2.9413 $\AA$, and the angles of $\mathrm{D}-\mathrm{H}^{\cdots} \mathrm{A}$ are in the rage of $120.09^{\circ}$ $166.93^{\circ}$. The detail hydrogen bondings of the complexes are listed in Tables S7-S12. All these are comparable with those found in other reported lanthanide sulfate complexes [55,60-62]. 
Structure of $\operatorname{EuK}\left(\mathrm{SO}_{4}\right)_{2}$ (6)

The structure of $\mathbf{6}$ reveals that it is a 3-D framework complex. The asymmetric unit of 6 contains one $\mathrm{Eu}^{3+}$ cation, one $\mathrm{K}^{+}$cation and two $\mathrm{SO}_{4}^{2-}$ anions. The metal atom is eight-coordinated by the oxygen atoms from seven sulfate ions as can be seen in Figure 2(a). Thus, two of the sulfur atoms in the asymmetric unit S1 forms four S-O-Ln bonds to four crystallographically distinct Ln atoms, thereby sharing corners with four metal-oxygen polyhedra. The S2 forms four S-O-Ln bonds to three unique metal atoms, sharing the corners with two metal-oxygen polyhedra and the edge with another polyhedron (Scheme 3(a) and (b)). The Eu-O bond distances are in the range of $2.325(5)-2.566(8) \AA$ (av.
2.416(1) $\AA$ ). The O-Eu-O bond angles are in the range of $55.6(2)-158.8(3)^{\circ}$. The selected bond distances and angles are given in Table $4 . \mathrm{LnO}_{8}$ polyhedra are linked by the $\mathrm{S}(1) \mathrm{O}_{4}$ tetrahedra in two-dimensions to form fourmembered rings, the rings connected by $\mathrm{S}(2) \mathrm{O}_{4}$ to form layers parallel to the bc-plane of the unit cell. Such a connectivity between the four-membered rings results in the formation of six four-membered rings around each eight-membered ring (Figure 2(b)). The layers are stacked over one another in AAA... fashion, with two adjacent layers separated by a unit cell length along the a-axis of the unit cell, thus forming four and eightmembered channels. The $\mathrm{S}(1) \mathrm{O}_{4}$ tetrahedra share corners and the $\mathrm{S}(2) \mathrm{O}_{4}$ tetrahedra share corners and edges with

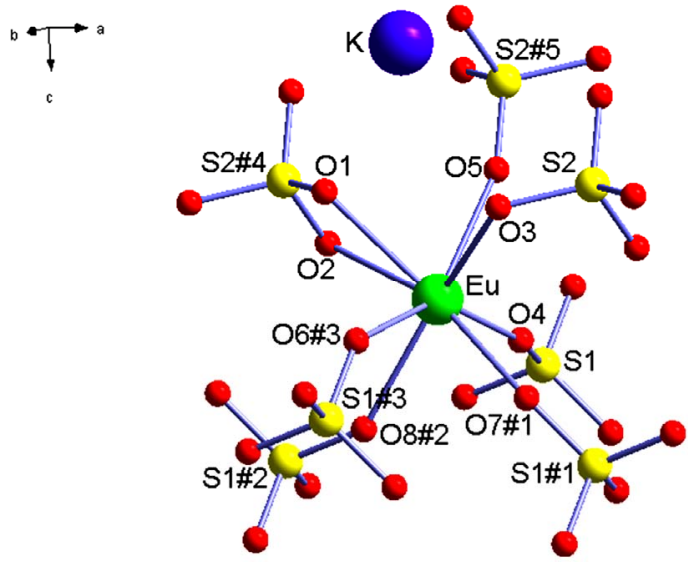

(a)

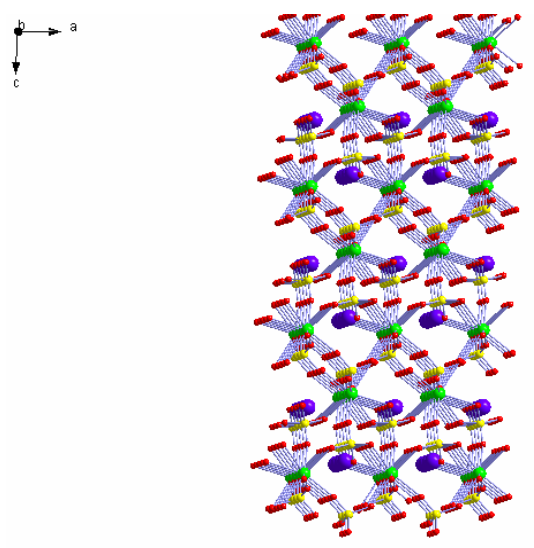

(c)

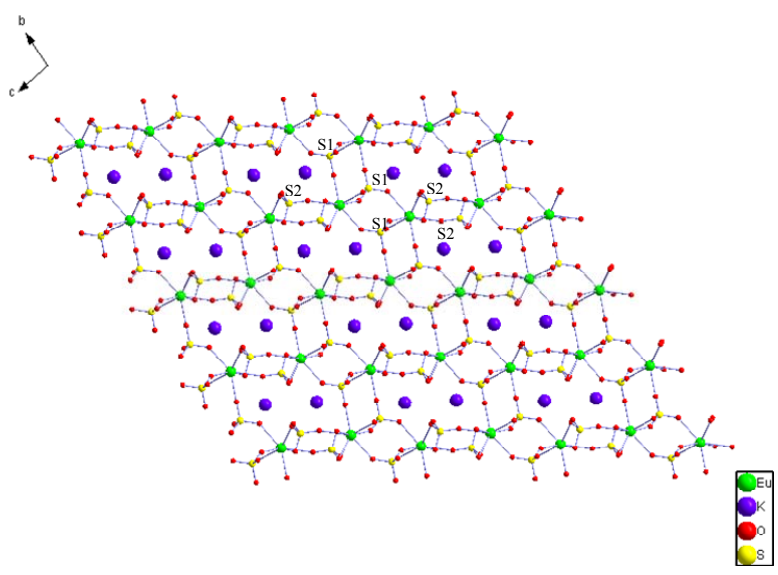

(b)

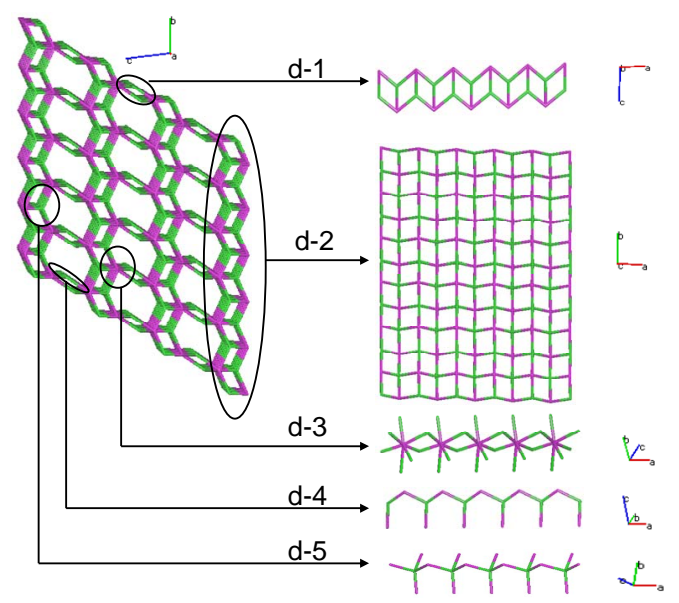

(d)

Figure 2. (a) The ORTEP view of the coordination environment of Eu in complex 6. (Symmetry codes: $\# 1$ : $-\mathrm{x}+2,-\mathrm{y},-\mathrm{z}+2$; \#2: $-\mathrm{x}+$ $1,-\mathrm{y},-\mathrm{z}+2$; \#3: $\mathrm{x}, \mathrm{y}+1, \mathrm{z} ; \# 4: \mathrm{x}-1, \mathrm{y}, \mathrm{z} ; \# 5:-\mathrm{x}+2,-\mathrm{y},-\mathrm{z}+1)$; (b) The layer, parallel to the bc-plane of the unit cell in I, formed by connecting $\mathrm{EuO}_{8}$ polyhedra with $\mathrm{SO}_{4}$ tetrahedra, by sharing edges and vertices, and thereby forming four-membered and eight-membered rings. Note the arrangement of the four-membered rings around the eight-membered rings. The kalium cations are shown in one eight-membered rings. (c) The three-dimensional framework formed by the linking of the layers, stacked one over another, along the a-axis of the unit cell by the sulfate groups. (d) Schematic representation of the $3 \mathrm{D}\left(4^{3}\right)\left(4^{5} .6\right)\left(4^{8} .6^{9} .8^{4}\right)$ topology network in complex 6. Fuchia, Eu; Lime, $\mathrm{SO}_{4}^{2-}$. (d-1) The 1D zig-zig chains in the ac plane. (d-2) The 2D wavelike layer in the ab plane. (d-3) A 7-connected metal mode containing one europium center with seven $\mathrm{SO}_{4}^{2-}$. (d-4) A 3-connected ligand node containing one $\mathrm{SO}_{4}^{2-}$ with three samarium center. (d-5) A 4-connected ligand node containing one $\mathrm{SO}_{4}^{2-}$ with four europium center. 
the metal-oxygen polyhedra respectively from adjacent layers, thereby connecting the layers and forming a threedimensional framework (Figure 2(c)). This connectivity gives rise to a square grid of intersecting four membered channels running perpendicular to one an other, and intersecting the channels along the a-axis of the unit cell. The kalium cations are located in the cages formed by the eight-membered channels.

Each $\mathrm{S}(1) \mathrm{O}_{4}$ links four adjacent $\mathrm{Eu}$ atoms to afford an infinite wavelike 2D layer in an ab plane (Figure 2(d)-2). Then $\mathrm{S}(2) \mathrm{O}_{4}$ between the adjacent layers links three $\mathrm{Eu}$ atoms in zig-zig $1 \mathrm{D}$ chains in ac planes to construct a $3 \mathrm{D}$ framework (Figure 2(d)-1). In this case, $\mathrm{S}(1) \mathrm{O}_{4}$ ligands can be regarded as 4-connected nodes (Figure 2(d)-5), $\mathrm{S}(2) \mathrm{O}_{4}$ ligands can be regarded as 3-connected nodes (Figure 2(d)-4), and Eu atoms surrounded by seven $\mathrm{SO}_{4}^{2-}$ ligands can be considered as 7-connected nodes (Figure 2(d)-3). Topology analysis by the TOPOS4.0 software package suggests that $\mathrm{EuK}\left(\mathrm{SO}_{4}\right)_{2}$ possesses a 3D $(3,4,7)$-connected 3-nodel network with a $\left(4^{3}\right)\left(4^{5} .6\right)$ $\left(4^{8} .6^{9} \cdot 8^{4}\right)$ Schläfli symbol (Figure 2(d)).

\subsection{Photoluminescent Properties}

Lanthanide coordination polymers often exhibit intense luminescence and thereby are particularly interesting for luminescent materials. Owing to the excellent luminescent properties of $\mathrm{Tb}$ (III), Sm (III), Dy (III) and Eu (III) ions, the photoluminescent behaviors of the coordination polymers $3,4,5,6$ were investigated in the form of a solid state at room temperature.

The luminescent spectrum of complex $\mathbf{3}$ was investigated under excitation of $368 \mathrm{~nm}$ with a slit width $(2.5: 2.5)$. In Figure 3 it can be seen that emission peaks at $491 \mathrm{~nm}, 545 \mathrm{~nm}, 587 \mathrm{~nm}$ and $622 \mathrm{~nm}$ are attributed to the characteristic emissions of $\mathrm{Tb}$ emissive state ${ }^{5} \mathrm{D}_{4}$ to the ground state ${ }^{7} \mathrm{~F}_{\mathrm{J}}(\mathrm{J}=6 \rightarrow 3)$, respectively. The spectra are dominated by the ${ }^{5} \mathrm{D}_{4} \rightarrow{ }^{7} \mathrm{~F}_{5}$ transitions at $545 \mathrm{~nm}$ which create the intense green luminescence output for the solid sample. In addition, there exists a weak luminescence emission at $417 \mathrm{~nm}$ assigned to intraligand $\pi \rightarrow \pi^{*}$ transition, implying that the energy is not fully transferred from the sulfate ion to the $\mathrm{Tb}$ ion.

The emission spectrum involving complex 4 was determined on excitation at $367 \mathrm{~nm}$ with a slit width $(2.5: 2.5)$, which is depicted in Figure 4. As expected, the<smiles>[AlH2]O[Pb](O[AlH2])(O[AlH2])O[AlH2]</smiles>

(a)

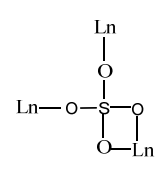

(b)

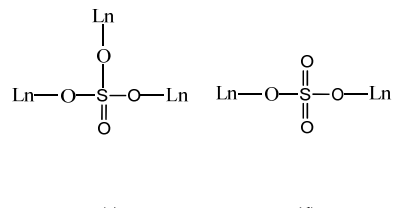

(c) (d)
Scheme 3. The four kinds of coordination modes of sulfate ions coordinated to lanthanide ions.

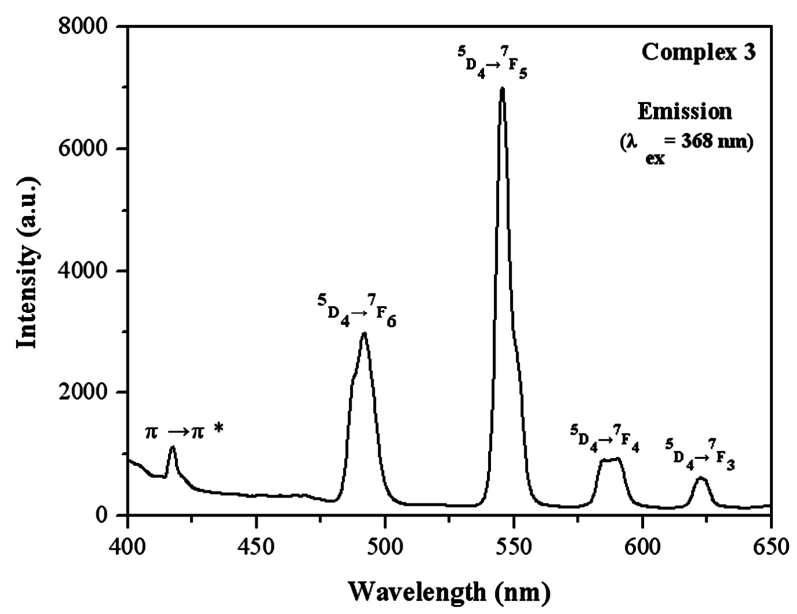

Figure 3. Photoluminescence emission spectra for complex $\mathbf{3}$ in the solid state at room temperature.

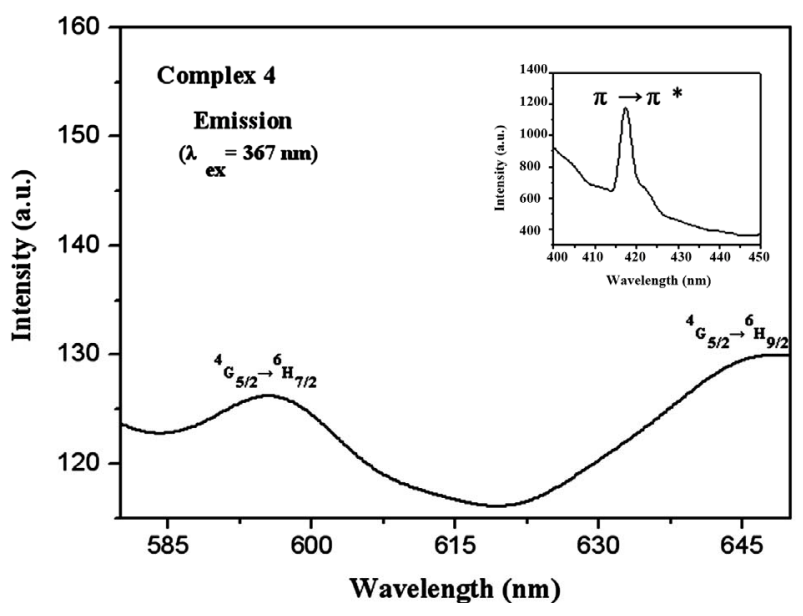

Figure 4. Photoluminescence emission spectra for the complex 4 in the solid state at room temperature.

two luminescence emission peaks at 595 and $647 \mathrm{~nm}$ correspond to the characteristic emissions of Sm emissive state ${ }^{4} \mathrm{G}_{5 / 2}$ to the ${ }^{4} \mathrm{H}_{7 / 2}$ and ${ }^{4} \mathrm{H}_{9 / 2}$ levels, respectively. Similar to complex 3 , there also exists an intraligand $\pi \rightarrow \pi^{*}$ transition at $417 \mathrm{~nm}$, implying that the energy is not fully transferred from the sulfate ion to the $\mathrm{Sm}$ ion. Compared to those of the other three complexes, the emission spectrum of complex $\mathbf{3}$ showed very weak and broad.

With regard to the luminescent characteristic of the dysprosium complex, the luminescent spectra of complex 5 was determined under excitation of $240 \mathrm{~nm}$ with slit width $(2.5: 2.5)$. As shown in Figure 5, it presents good luminescent properties with a narrow, sharp and strong emission peak at $482 \mathrm{~nm}$ assigned to the blue insensitive transitions ${ }^{4} \mathrm{~F}_{9 / 2} \rightarrow{ }^{6} \mathrm{H}_{15 / 2}$. Additionally, it should be mentioned that no further emission peaks were observed, indicating that the energy is fully transferred from the sulfate ion to the Dy ion. This is different from the other three complexes in which the characteristic emission 
bands of the sulfates ions are found, suggesting that the more efficient ligand-to-metal energy transfers occur in dysprosium coordination polymer. Furthermore, the one strong emission band suggests that this homochromy effect possesses good optical application, which is rare in other dysprosium coordination polymers.

The luminescent properties regarding complex 6 were studied at the excitation wavelength of $370 \mathrm{~nm}$ with a slit width (2.5:2.5). Figure 6 gives the emission spectra of this complex. The characteristic ${ }^{5} \mathrm{D}_{0} \rightarrow{ }^{7} \mathrm{~F}_{\mathrm{J}}(\mathrm{J}=1 \rightarrow 4)$ transitions of the $\mathrm{Eu}(\mathrm{IIII})$ ions at 595, 619, 653, and 689 $\mathrm{nm}$ show well an efficient ligand-to-Eu energy transfer. The quite weak emission peak ${ }^{5} \mathrm{D}_{0} \rightarrow{ }^{7} \mathrm{~F}_{0}$ at $580 \mathrm{~nm}$ are attributed to the symmetry-forbidden emission of the $\mathrm{Eu}(\mathrm{III})$ ions in these coordination polymers. The ${ }^{5} \mathrm{D}_{0} \rightarrow$ ${ }^{7} \mathrm{~F}_{1}$ emission bands pertain to the prominent magnetic dipole transitions, which are almost unin- fluenced by the coordination environment. On the other hand, the outstanding ${ }^{5} \mathrm{D}_{0} \rightarrow{ }^{7} \mathrm{~F}_{2}$ emission bands, possessing a strong electric dipole character, are hypersensitive to

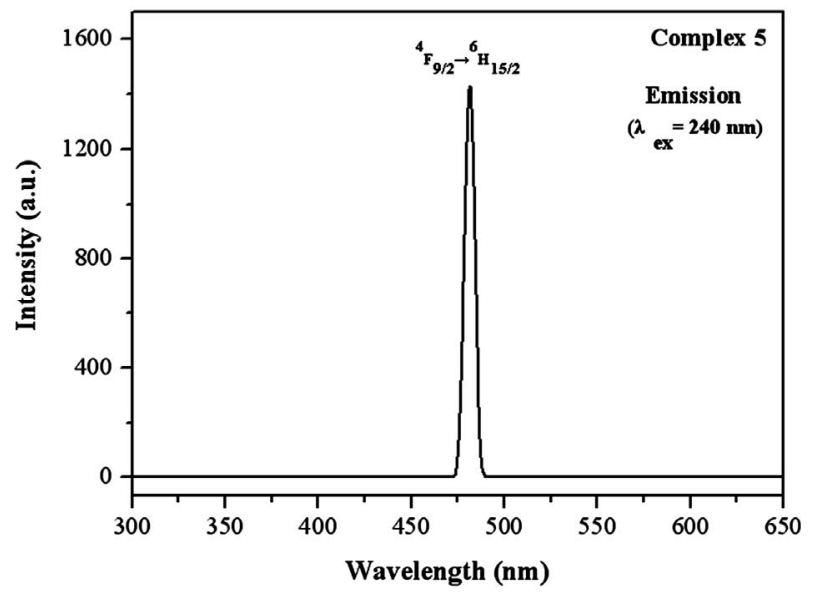

Figure 5. Photoluminescence emission spectrum for complex 5 in the solid state at room temperature.

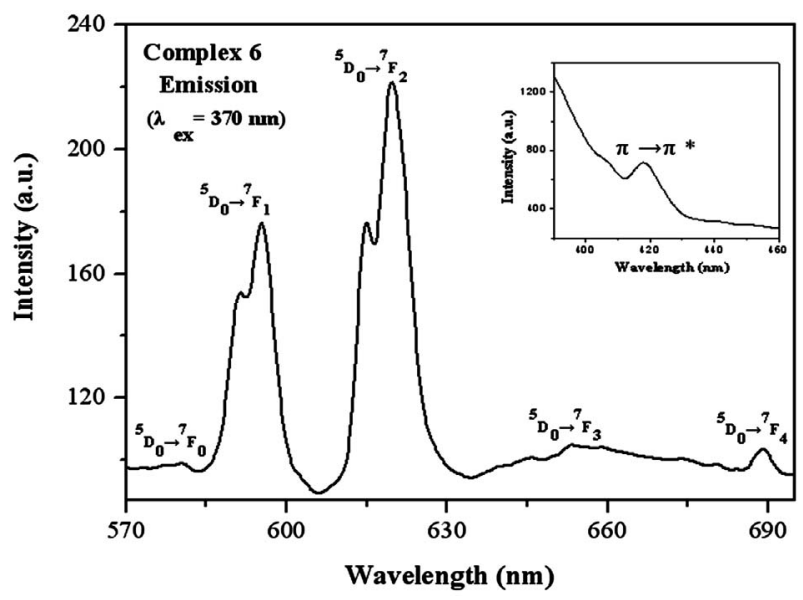

Figure 6. Photoluminescence emission spectra for complex 6 in the solid state at room temperature. the coordination environment. Therefore, we can take advantage of the relative intensity disparity of these transitions to probe the nature of the linker environment and herein Eu luminescence can act as a sensitive probe of the lanthanide coordination environment $[63,64]$. In particular, the ratio of the intensities of the $\left({ }^{5} \mathrm{D}_{0} \rightarrow{ }^{7} \mathrm{~F}_{2}\right)$ : $\left({ }^{5} \mathrm{D}_{0} \rightarrow{ }^{7} \mathrm{~F}_{1}\right)$ transition is very sensitive to the symmetry of the $\mathrm{Eu}(\mathrm{III})$ center. In the spectra, it can be obviously seen that the intensity of the electric dipole transitions ${ }^{5} \mathrm{D}_{0} \rightarrow$ ${ }^{7} \mathrm{~F}_{2}$ are much stronger than that of the magnetic dipole transition ${ }^{5} \mathrm{D}_{0} \rightarrow{ }^{7} \mathrm{~F}_{1}$, which implies that the Eu(III) ions in these complexes are located in lower symmetric coordination environments. This is in agreement with the result of the single X-ray analysis. Additionally, the strongest emission peaks in the ${ }^{5} \mathrm{D}_{0} \rightarrow{ }^{7} \mathrm{~F}_{1}$ and ${ }^{5} \mathrm{D}_{0} \rightarrow{ }^{7} \mathrm{~F}_{2}$ transition region generate splitting of energy, which can be also ascribed to the $\mathrm{Eu}(\mathrm{III})$ centers in asymmetric sites in these complexes. Among these emission lines, ${ }^{5} \mathrm{D}_{0} \rightarrow$ ${ }^{7} \mathrm{~F}_{2}$ transitions are most striking, indicating intense red luminescence of complex 6. Additionally, there also exits a $\pi \rightarrow \pi^{*}$ transition, which is similar to that of the complex 3 and 4.

\subsection{TG Properties}

Thermal analysis shows that the complexes are considerably stable, especially complex 6. As shown in Figure $7(\mathbf{a})$, the weight loss of $20.01 \%$ in the range $91^{\circ} \mathrm{C}$ $294^{\circ} \mathrm{C}$ can be attributed to the loss of the coordinated water molecules (cal. 21.07\%). Then the complexes stayed at a very stable stage until $800^{\circ} \mathrm{C}$. The collapse of the fragment in the second stage may be due to the loss of $\mathrm{SO}_{3}$, and the final residual is $\mathrm{Ln}_{2} \mathrm{O}_{3}$. In comparison, the thermal stability of complex $\mathbf{6}$ is better, and it didn't decompose until $700^{\circ} \mathrm{C}$ because of the absence of water in the structure (Figure 7(b)).

\subsection{Catalysis Study}

In the primary stage of our work, the oxidation reaction of cyclohexane to produce cyclohexanone and cyclohexanol was employed as a model reaction and complex 1 was examined as a catalyst. The reaction was carried out in a solvent of $\mathrm{CH}_{3} \mathrm{CN}$ at 40 centigrade. It showed small TON value, indicating that the capability of the catalysts for the reaction of cyclohexane conversion is weak. A blank experiment conducted in the absence of the catalyst, under the above reaction conditions, found that no products were detected. For the sake of compareson, complexes 2-8 were also used as catalysts. As shown in Table 7, similarly, there is very low catalytic activity with TON values in the range of $0.68-4.83$, although cyclohexane can reach high conversion after the reaction for some time. It is found that the order of the catalytic activity is $8>\mathbf{2}>\mathbf{5}>\mathbf{3}>\mathbf{7}>\mathbf{4}>\mathbf{6}>\mathbf{1}$ when 


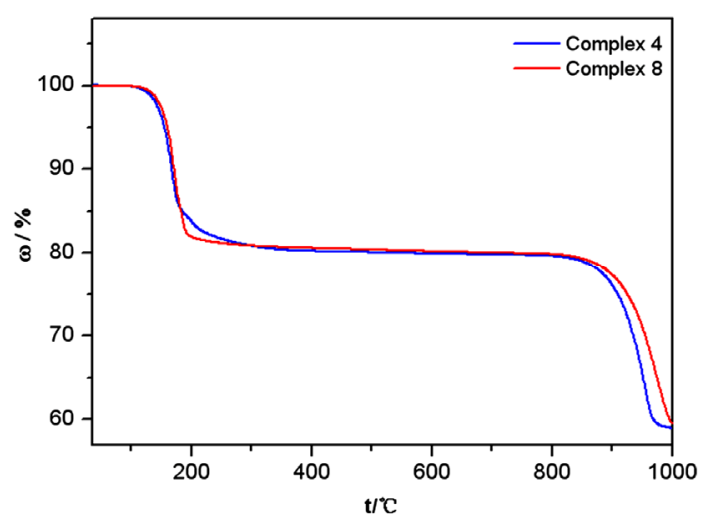

(a)

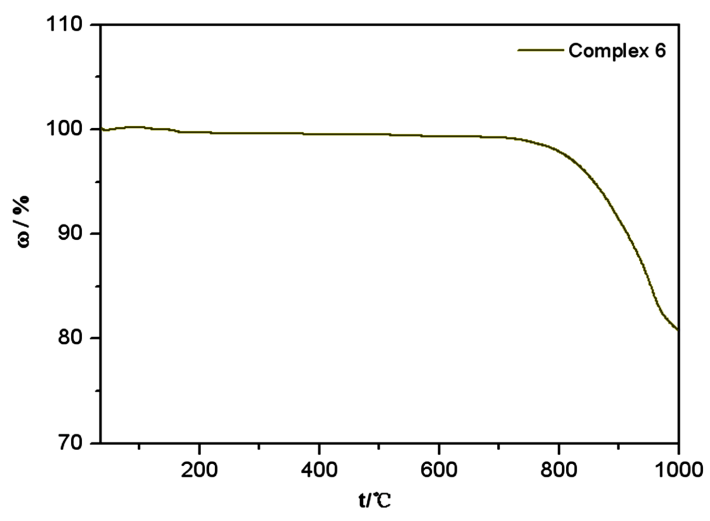

(b)

Figure 7. (a) TG curve of $\mathrm{Ln}_{2}\left(\mathrm{SO}_{4}\right)_{3}\left(\mathrm{H}_{2} \mathrm{O}\right)_{8}(\mathrm{Ln}=\mathrm{Sm}(4)$, $\mathrm{Ho}(8))$; (b) TG curve of $\mathrm{EuK}\left(\mathrm{SO}_{4}\right)_{2}(6)$.

Table 7. Data of oxidation for cyclohexane with complexes 1-8 as catalysts in the system of $/ \mathrm{H}_{2} \mathrm{O}_{2} / \mathrm{HNO}_{3} / \mathrm{CH}_{3} \mathrm{CN}$ at $40^{\circ} \mathrm{C}^{*}$.

\begin{tabular}{|c|c|c|c|c|c|c|c|c|c|}
\hline \multirow[b]{2}{*}{ Catalysts } & \multicolumn{3}{|c|}{ Mole ratio } & \multirow[b]{2}{*}{$\begin{array}{l}\text { Time } \\
\text { (h) }\end{array}$} & \multirow[b]{2}{*}{$\begin{array}{l}\text { Reaction } \\
\text { medium }\end{array}$} & \multirow{2}{*}{$\begin{array}{c}\text { Cyclohexane } \\
\text { Conversion } \\
(\%)\end{array}$} & \multirow{2}{*}{$\begin{array}{c}\text { TON } \\
\text { (Cyclohexanone) }\end{array}$} & \multirow[b]{2}{*}{$\begin{array}{c}\text { TON } \\
\text { (Cyclohexanol) }\end{array}$} & \multirow{2}{*}{$\begin{array}{c}\text { TON } \\
\text { (Cyclohexanol } \\
\text { and Cyclohexanone) }\end{array}$} \\
\hline & $\begin{array}{c}\text { Catalyst/ } \\
\text { Cyclohexane } \\
\left(10^{-5}\right)\end{array}$ & $\begin{array}{c}\text { Catalyst } / \mathrm{H}_{2} \mathrm{O}_{2} \\
\left(10^{-6}\right)\end{array}$ & $\begin{array}{l}\text { Catalyst } \\
/ \mathrm{HNO}_{3} \\
\left(10^{-4}\right)\end{array}$ & & & & & & \\
\hline 1 & 6.52 & 1 & 2.5 & 16 & $\mathrm{CH}_{3} \mathrm{CN}$ & 99.88 & 0 & 0.68 & 0.68 \\
\hline 2 & 6.52 & 1 & 2.5 & 16 & $\mathrm{CH}_{3} \mathrm{CN}$ & 99.95 & 0.27 & 4.56 & 4.83 \\
\hline 3 & 6.52 & 1 & 2.5 & 16 & $\mathrm{CH}_{3} \mathrm{CN}$ & 99.92 & 0.06 & 3.43 & 3.49 \\
\hline 4 & 6.52 & 1 & 2.5 & 16 & $\mathrm{CH}_{3} \mathrm{CN}$ & 99.94 & 0 & 2.09 & 2.09 \\
\hline 5 & 6.52 & 1 & 2.5 & 16 & $\mathrm{CH}_{3} \mathrm{CN}$ & 99.95 & 0 & 4.19 & 4.19 \\
\hline 6 & 6.52 & 1 & 2.5 & 16 & $\mathrm{CH}_{3} \mathrm{CN}$ & 99.95 & 0 & 1.67 & 1.67 \\
\hline 7 & 6.52 & 1 & 2.5 & 16 & $\mathrm{CH}_{3} \mathrm{CN}$ & 99.94 & 0.13 & 2.51 & 2.64 \\
\hline 8 & 6.52 & 1 & 2.5 & 16 & $\mathrm{CH}_{3} \mathrm{CN}$ & 99.94 & 0.18 & 4.65 & 4.83 \\
\hline
\end{tabular}

* $1: \mathrm{Pr}_{2}\left(\mathrm{SO}_{4}\right)_{3}\left(\mathrm{H}_{2} \mathrm{O}\right)_{8} ; 2: \mathrm{Nd}_{2}\left(\mathrm{SO}_{4}\right)_{3}\left(\mathrm{H}_{2} \mathrm{O}\right)_{8} ; 3: \mathrm{Tb}_{2}\left(\mathrm{SO}_{4}\right)_{3}\left(\mathrm{H}_{2} \mathrm{O}\right)_{8} ; 4: \mathrm{Sm}_{2}\left(\mathrm{SO}_{4}\right)_{3}\left(\mathrm{H}_{2} \mathrm{O}\right)_{8} ; 5: \mathrm{Dy}_{2}\left(\mathrm{SO}_{4}\right)_{3}\left(\mathrm{H}_{2} \mathrm{O}\right)_{8} ; 6: \mathrm{Eu}\left(\mathrm{SO}_{4}\right)_{2} \mathrm{~K} ; 7: \mathrm{Gd}_{2}\left(\mathrm{SO}_{4}\right)_{3}\left(\mathrm{H}_{2} \mathrm{O}\right)_{8} ; 8: \mathrm{Ho}_{2}\left(\mathrm{SO}_{4}\right)_{3}$ $\left(\mathrm{H}_{2} \mathrm{O}\right)_{8}$. TON: moles of products (cyclohexanol and cyclohexanone)/moles of catalysts.

comparing the catalytic activity of the complexes 1-8. In particular, the catalytic efficiency of the complexes $\mathbf{2}$ and 8 is found to be much better than other complexes. The results also showed that in the cases of $\mathbf{1}, \mathbf{4 , 5}$ and $\mathbf{6}$, the final products were only cyclohexanol, which indicated that the selectivity of those complexes is very high, and therefore, complexes of 1, 4, 5 and 6 may possess a value for potential application.

\section{CONCLUSION}

In summary, we have reported two kinds of simple, high-yield and pure phase synthesis of 2-D and 3-D framework lanthanide sulphate coordination complexes, $\mathrm{Ln}_{2}\left(\mathrm{SO}_{4}\right)_{3}\left(\mathrm{H}_{2} \mathrm{O}\right)_{8}(\mathrm{Ln}=\operatorname{Pr}(\mathbf{1}), \mathrm{Nd}(\mathbf{2}), \mathrm{Tb}(3), \mathrm{Sm}$ (4), Dy (5), $\mathrm{Gd}(7), \mathrm{Ho}(\mathbf{8}))$ and $\mathrm{EuK}\left(\mathrm{SO}_{4}\right)_{2}(\mathbf{6})$. The synthesis of all complexes have demonstrated that the lanthanide sulfate complexes were designed and prepared by using appropriate solvent and SDAs. On the other hand, all these complexes represent a certain activity in catalysis. These $\mathrm{Tb}, \mathrm{Sm}$, Dy and Eu complexes exhibit different luminescence characterizations of $\mathrm{Tb}^{3+}, \mathrm{Sm}^{3+}, \mathrm{Dy}^{3+}$ and $\mathrm{Eu}^{3+}$, respectively. The luminescence in the solid state indicates the complex $\mathbf{5}$ is an excellent candidate for pure fluorescent materials.

\section{ACKNOWLEDGEMENTS}

This work was supported by grants from the National Natural Science Foundation of China (Grant No. 21071071) and the State Key Laboratory of Inorganic Synthesis and Preparative Chemistry, College of Chemistry, Jilin University, Changchun 130012, P. R. China (Grant No. 2013-05).

\section{REFERENCES}

[1] Zhou, H.C., Long, J.R. and Yaghi, O.M. (2012) Introduction to metal-organic frameworks. Chemical Reviews, 
112, 673-674. http://dx.doi.org/10.1021/cr300014x

[2] Rosi, N.L., Ecket, J., Eddaoudi, M., Vodak, D.T., Kim, J., O'Keeffe, M. and Yaghi, O.M. (2003) Microporous metal-organic frameworks. Science, 300, 1127-1129. http://dx.doi.org/10.1126/science.1083440

[3] Dincä, M., Dailly, A., Liu, Y., Brown, C.M., Neumann, D.A.and Long, J.R. (2006) Hydrogen storage in a microporous metal-organic framework with exposed $\mathrm{Mn}^{2+}$ coordination sites. Journal of the American Chemical Society, 128, 16876-16883.

http://dx.doi.org/10.1021/ja0656853

[4] Collins, D.J. and Zhou, H.C. (2007) Hydrogen storage in metal-organic frameworks. Journal of Materials Chemistry, 17, 3154-3160. http://dx.doi.org/10.1039/b702858j

[5] Lin, J.D., Cheng, J.W. and Du, S.W. (2008) Five $\mathrm{d}^{10}$ 3D metal-organic frameworks constructed from aromatic polycarboxylate acids and flexible imidazole-based ligands. Crystal Growth and Design, 8, 3345-3353.

http://dx.doi.org/10.1021/cg8002614

[6] Sun, Y.Q., Zhang, J. and Yang, G.Y. (2006) A series of luminescent lanthanide-cadmium-organic frameworks with helical channels and tubes. Chemical Communications, 4700-4702. http://dx.doi.org/10.1039/b610892j

[7] Kuppler, R.J., Timmons, D.J., Fang, Q.R., Li, J.R., Makal, T.A., Young, M.D., Yuan, D.Q., Zhao, D., Zhuang, W.J. and Zhou, H.C. (2009) Potential applications of metalorganic frameworks. Coordination Chemistry Reviews, 253, 3042-3066. http://dx.doi.org/10.1016/j.ccr.2009.05.019

[8] Li, J.R., Kuppler, R.J. and Zhou, H.C. (2009) Selective gas adsorption and separation in metal-organic frameworks. Chemical Society Reviews, 38, 1477-1504. http://dx.doi.org/10.1039/b802426j

[9] Férey, G. (2008) Hybrid porous solids: Past, present, future. Chemical Society Reviews, 37, 191-214. http://dx.doi.org/10.1039/b618320b

[10] Furukawa, H., Ko, N., Go, Y.B., Aratani, N., Choi, S.B., Choi, E., Yazaydin, A.O., Snurr, R.Q., O'Keeffe, M., Kim, J. and Yaghi, O.M. (2010) Ultra-high porosity in metal-organic frameworks. Science, 239, 424-428. http://dx.doi.org/10.1126/science.1192160

[11] Kuriki, K., Koike, Y. and Okamoto, Y. (2002) Plastic optical fiber lasers and amplifiers containing lanthanide complexes. Chemical Reviews, 102, 2347-2356. http://dx.doi.org/10.1021/cr010309g

[12] Bünzli, J.C.G. (2006) Benefiting from the unique properties of lanthanide ions. Accounts of Chemical Research, 39, 53-61. http://dx.doi.org/10.1021/ar0400894

[13] Plečnik, C.E., Liu, S.M. and Shore, S.G. (2003) Lanthanide-transition-metal complexes: From ion pairs to extended arrays. Accounts of Chemical Research, 36, 499508. http://dx.doi.org/10.1021/ar010050o

[14] Winpenny, R.E.P. (1998) The structures and magnetic properties of complexes containing $3 \mathrm{~d}$ - and $4 \mathrm{f}$-metals. Chemical Society Reviews, 27, 447-452. http://dx.doi.org/10.1039/a827447z

[15] Li, G.M., Akitsu, T., Sato, O. and Einaga, Y. (2003) Pho- toinduced Magnetization for Cyano-bridged 3d-4f Hetero-bimetallic Assembly $\mathrm{Nd}(\mathrm{DMF})_{4}(\mathrm{~m}-\mathrm{CN})_{5} \mathrm{Fe}(\mathrm{CN})_{5} \cdot \mathrm{H}_{2} \mathrm{O}$ (DMF=N,N-dimethylformamide). Journal of the American Chemical Society, 125, 12396-12397. http://dx.doi.org/10.1021/ja037183k

[16] Zhao, B., Chen, X.Y., Cheng, P., Liao, D.Z., Yan, S.P. and Jiang, Z.H. (2004) Coordination Polymers Containing 1D Channels as Selective Luminescent Probes. Journal of the American Chemical Society, 126, 15394-15395. http://dx.doi.org/10.1021/ja047141b

[17] Qi, Y., Che, Y.X. and Zheng, J.M. (2008) A zinc(II) coordination polymer constructed from mixed-ligand 1,2bis(2-(1H-imidazol-1-yl)ethoxy)ethane and 1,4-benzenedicarboxylic acid. CrystEngComm, 10, 1137-1139. http://dx.doi.org/10.1039/b801387j

[18] Henninger, S.K., Habib, H.A. and Janiak, C. (2009) MOFs as adsorbents for low temperature heating and cooling applications. Journal of the American Chemical Society, 131, 2776-2777. http://dx.doi.org/10.1021/ja808444z

[19] Ma, L.F., Wang, L.Y., Wang, Y.Y., Du, M. and Wang, J.G. (2009) Synthesis, structures and properties of Mn(II) coordination frameworks based on $\mathrm{R}$-isophthalate $(\mathrm{R}=$ $-\mathrm{CH}_{3}$ or $\left.-\mathrm{C}\left(\mathrm{CH}_{3}\right)_{3}\right)$ and various dipyridyl-type co-ligands. CrystEngComm, 11, 109-117. http://dx.doi.org/10.1021/ja808444z

[20] Habib, H.A., Sanchiz, J. and Janiak, C. (2009) Magnetic and luminescence Properties of $\mathrm{Cu}(\mathrm{II}), \mathrm{Cu}(\mathrm{II})_{4} \mathrm{O}_{4}$ core and $\mathrm{Cd}(\mathrm{II})$ mixed-ligand metal-organic frameworks constructed from 1,2-bis(1,2,4-triazol-4-yl)ethane and benzene-1,3,5-tricarboxylate. Inorganica Chimica Acta, 362 , 2452-2460. http://dx.doi.org/10.1016/i.ica.2008.11.003

[21] Habib, H.A., Hoffmann, A., Hoppe, H.A. and Janiak, C. (2009) Crystal structures and solid-state CPMAS ${ }^{13} \mathrm{C}$ NMR correlations in luminescent zinc(II) and cadmium(II) mixed-ligand coordination polymers constructed from 1,2bis(1,2,4-triazol-4-yl)ethane and benzenedicarboxylate. Dalton Transactions, 1742-1751. http://dx.doi.org/10.1039/b812670d

[22] Habib, H.A., Sanchiz, J. and Janiak, C. (2008) Mixedligand coordination polymers from 1,2-bis(1,2,4-triazol-4-yl) ethane and benzene-1,3,5-tricarboxylate: Trinuclear nickel or zinc secondary building units for three-dimensional networks with crystal-to-crystal transformation upon dehydration. Dalton Transactions, 1734-1744. http://dx.doi.org/10.1039/b715812b

[23] Zhang, L.P., Yang, J., Ma, J.F., Jia, Z.F., Xie, Y.P. and Wei, G.H. (2008) A series of 2D and 3D metal-organic frameworks based on different polycarboxylate anions and a flexible 2,2'-bis( $1 H$-imidazolyl $)$ ether ligand. CrystEngComm, 10, 1410-1420. http://dx.doi.org/10.1039/b804578j

[24] Wisser, B., Lu, Y. and Janiak, C. (2007). Chiral Coordination Polymers with Amino Acids: ${ }_{\infty}^{2}\left[\mathrm{Cu}_{2}(\mu\right.$-L-tryptophanato $)_{2}(\mu-4,4$ '-bipyridine $\left.)\left(\mathrm{H}_{2} \mathrm{O}\right)_{2}\right]\left(\mathrm{NO}_{3}\right)_{2}$. Zeitschrift für Anorganishe und Allgemeine Chemie, 633, 1189-1192.

[25] Manna, S.C., Okamoto, K.I., Zangrando, E. and Chaudhuri, N.R. (2007) Conformational morphosis in azocalix [4]arenes. CrystEngComm, 9, 199-122. 
[26] Chen, Z.F., Zhang, S.F., Luo, H.S., Abrahams, B.F. and Liang, H. (2007) $\mathrm{Ni}_{2}\left(\mathrm{R}^{*} \mathrm{COO}\right)_{4}\left(\mathrm{H}_{2} \mathrm{O}\right)(4,4 \text { '-bipy })_{2}-\mathrm{A}$ robust homochiral quartz-like network with large chiral channels. CrystEngComm, 9, 27-29. http://dx.doi.org/10.1039/b613047j

[27] Pichon, A., Fierro, C.M., Nieuwenhuyzen, M. and James, S. (2007) A pillared-grid MOF with large pores based on the $\mathrm{Cu}_{2}\left(\mathrm{O}_{2} \mathrm{CR}\right)_{4}$ paddle-wheel. CrystEngComm, 9, 449451. http://dx.doi.org/10.1039/b702176c

[28] Pasán, J., Sanchiz, J., Lloret, F., Julve, M. and Ruiz-Pérez, C. (2007) Crystal engineering of 3-D coordination polymers by pillaring ferromagnetic copper(II)-methylmalonate layers. CrystEngComm, 9, 478-487.

http://dx.doi.org/10.1039/b701788j

[29] Stephenson, M.D. and Hardie, M.J. (2006) Coordination and hydrogen bonded network structures of $\mathrm{Cu}(\mathrm{II})$ with mixed ligands: A hybrid hydrogen bonded material, an infinite sandwich arrangement, and a 3-D net. Dalton Transactions, 3407-3417. http://dx.doi.org/10.1039/b600357e

[30] Carballo, R, Covelo, B, Vázquez-López, E.M., GarcíaMartínez, E., Castiñeiras, A., Janiak, C. (2005) Zeitschrift für Anorganishe und Allgemeine Chemie, 631, 19291931.

[31] Yao, J., Lu, Z.D., Li, Y.Z., Lin, J.G., Duan, X.Y., Gao, S., Meng, Q.J. and Lu, C.S. (2008) Three-dimensional metal-organic frameworks constructed from bix and 1,2,4benzenetricarboxylate. CrystEngComm, 10, 1379-1383. http://dx.doi.org/10.1039/b805263h

[32] Wei, G.H., Yang, J., Ma, J.F., Liu, Y.Y., Li, S.L. and Zhang, L.P. (2008) Syntheses, structures and luminescent properties of zinc(II) and cadmium(II) coordination complexes based on bis(imidazole) and different carboxylate ligands. Dalton Transactions, 3080-3092.

http://dx.doi.org/10.1039/b716657e

[33] Zhang, J.Y., Ma, Y., Cheng, A.L., Yue, Q., Sun, Q. and Gao, E.Q. (2008) A manganese(II) coordination polymer with mixed pyrimidine-2-carboxylate and oxalate bridges: synthesis, structure, and magnetism. Dalton Transactions, 2061-2066. http://dx.doi.org/10.1039/b717837a

[34] Roh, S.G., Nah, M.K., Oh, J.B., Baek, N.S., Park, K.M. and Kim, H.K. (2005) Synthesis, crystal structure and luminescence properties of a saturated dimeric $\operatorname{Er}($ III)chelated complex based on benzoate and bipyridine ligands. Polyhedron, 24, 137-142.

http://dx.doi.org/10.1016/j.poly.2004.10.014

[35] Qin, C., Wang, X.L., Wang, E.B. and Su, Z.M. (2005) A series of three-dimensional lanthanide coordination polymers with rutile and unprecedented rutile-related topologies. Inorganic Chemistry, 44, 7122-7129. http://dx.doi.org/10.1021/ic050906b

[36] Wan, Y.H., Jin, L.P. and Wang, K.Z. (2003) Hydrothermal synthesis and structural characterization of two novel lanthanide supramolecular coordination polymers with nano-chains. Journal of Molecular Structure, 649, 85-93. http://dx.doi.org/10.1016/S0022-2860(03)00021-8

[37] Wan, Y., Zhang, L., Jin, L., Gao, S. and Lu, S. (2003) High-dimensional architectures from the self-assembly of lathanide ions with benzenedicarboxylates and 1,10- phenanthroline. Inorganic Chemistry, 42, 4985-4994. http://dx.doi.org/10.1021/ic034258c

[38] Eddaoudi, M., Kim, J., Wachter, J.B., Chae, H.K., O'Keeffe, M. and Yaghi, O.M. (2001) Porous Metal-organic polyhedra: $25 \AA$ cuboctahedron constructed from $12 \mathrm{Cu}_{2}\left(\mathrm{CO}_{2}\right)_{4}$ paddle-wheel building blocks. Journal of the American Chemical Society, 123, 4368-4369. http://dx.doi.org/10.1021/ja0104352

[39] Guo, X.D., Zhu, G.S., Sun, F.X., Li, Z.Y., Zhao, X.J., Li, X.T., Wang, H.C. and Qiu, S.L. (2006) Synthesis, structure, and luminescent properties of microporous lanthanide metal-organic frameworks with inorganic rod-shaped building units. Inorganic Chemistry, 45, 2581-2587. http://dx.doi.org/10.1021/ic0518881

[40] Thirumurugan, A. and Natarajan, S. (2004) Terephthalate bridge frameworks of $\mathrm{Nd}$ and $\mathrm{Sm}$ phthalates. Inorganic Chemistry Communications, 7, 395-399. http://dx.doi.org/10.1016/j.inoche.2003.12.023

[41] Zhang, Z.H., Okamura, T.A., Hasegawa, Y., Kawaguchi, H., Kong, L.Y., Sun, Y.W. and Ueyama, N. (2005) Syntheses, structures, and luminescent and magnetic properties of novel three-dimensional lanthanide complexes with 1,3,5-benzenetriacetate. Inorganic Chemistry, 44, 6219-6227. http://dx.doi.org/10.1021/ic050453a

[42] Cao, R., Sun, D., Liang, Y., Hong, M., Tatsumi, K. and Shi, Q. (2002) Syntheses and characterizations of threedimensional channel-like polymeric lanthanide complexes constructed by 1,2,4,5-benzenetetracarboxylic acid. Inorganic Chemistry, 41, 2087-2094. http://dx.doi.org/10.1021/ic0110124

[43] Cañadillas-Delgado, L., Fabelo, Ó., Ruíz-Pérez, C., Delgado, F.S., Julve, M., Hernndez-Molina, M., Laz, M.M. and Lorenzo-Luis, P. (2006) Zeolite-like nanoporous gadolinium complexes incorporating alkaline cations. Crystal Growth and Design, 6, 87-93. http://dx.doi.org/10.1021/cg050170t

[44] Tang S.F. and Mudring A.V. (2009) The missing link crystallized from the ionic liquid 1-ethyl-3-methylamonium tosylate: Bis-aqua-(p-toluenesulfonato-o)-europium(III)bis-toluenesulfonate dehydrate. Crystal Growth and Design, 9, 2549-2557.

[45] Wang, Z., Bai, F.Y., Xing, Y.H., Xie, Y., Ge, M.F. and Niu, S.Y. (2010) Two New 3D Lanthanide Coordination Polymers with Benzenesulfonic and Adipic Acids: Synthesis, Structure and Luminescent Properties. Zeitschrift für Anorganishe und Allgemeine Chemie, 636, 15701575 .

[46] Zhou, R.S., Ye, L., Ding, H., Song, J.F., Xu, X.Y. and Xu, J.Q. (2008) Sytheses, structures, luminescence, and magnetism of four 3D lanthanide 5-sulfosalicylates, Journal of Solid State Chemistry, 181, 567-575. http://dx.doi.org/10.1016/j.jssc.2007.12.027

[47] Lu, Z., Wen, L., Yao, J., Zhu, H. and Meng, Q. (2006) Two types of novel layer framework structures assembled from 5-sulfosalicylic acid and lanthanide ions. CrystEngComm, 8, 847-853. http://dx.doi.org/10.1039/b612147k

[48] Ma, J.F., Li, J.Y., Zheng G.L. and Liu J.F. (2003) The first ladder structure containing three different squares: The structure of barium 3-carboxy-4-hydroxybenzene- 
sulfonate. Inorganic Chemistry Communications, 6, 581583. http://dx.doi.org/10.1016/S1387-7003(03)00044-3

[49] Ma, J.F., Yang, J., Li, S.L., Song, S.Y., Zhang, H.J., Wan, H.S. and Yang, K.Y. (2005) Two Coordination polymers of $\operatorname{Ag}(\mathrm{I})$ with 5-sulfosalicylic acid. Crystal Growth and Design, 5, 807-812. http://dx.doi.org/10.1021/cg049723a

[50] Gao, S., Zhu, Z.-B, Huo, L.-H. and Ng, S.W. (2005) Poly[[triaquabis $\left(\mu_{4}-3\right.$-carboxy-4-hydroxybenzenesulfonat o)disilver(I)] monohydrate]. Acta Crystallographica, 61, $\mathrm{m} 279-\mathrm{m} 281$.

http://dx.doi.org/10.1107/S1600536805000504

[51] Gao, S., Zhu, Z.-B., Huo, L.-H. and Ng, S.W. (2005) Poly[di- $\mu$-aqua-bis $\left(\mu_{8}\right.$-3-carboxylato-4-hydroxybenzenesu lfonato)tetrasilver(I)]. Acta Crystallographica, 61, m282m284. http://dx.doi.org/10.1107/S1600536805000516

[52] Borkowski, L.A. and Cahill, C.L. (2004) Poly [[aquaneodymium(III)]- $\mu_{3}$-decane-1,10-dicarboxylato- $\mu_{3}-9$-carbo xynonanecarboxylato]. Acta Crystallographica C, 60, m159-m161.

http://dx.doi.org/10.1107/S0108270104003427

[53] Cheetham, A.K., Férey, G. and Loiseau, T. (1999) OpenFramework Inorganic Materials. Angewandte Chemie International Edition, 38, 3268-3292. http://dx.doi.org/10.1002/(SICI)1521-3773(19991115)38: 22<3268::AID-ANIE3268>3.0.CO;2-U

[54] Chesnut, D.J., Hagrman, D., Zapf, P.J., Hammond, R.P., LaDuca, R. Jr., Haushalter, R.C., Zubieta, J. (1999) Organic/inorganic composite materials: The roles of organoamine ligands in the design of inorganic solids. Coordination Chemistry Reviews, 190-192, 737-769. http://dx.doi.org/10.1016/S0010-8545(99)00119-8

[55] Bataille, T. and Louër, D. (2002) Two new diamine templated lanthanum sulfates, $\mathrm{La}_{2}\left(\mathrm{H}_{2} \mathrm{O}\right)_{2}\left(\mathrm{C}_{4} \mathrm{H}_{12} \mathrm{~N}_{2}\right)\left(\mathrm{SO}_{4}\right)_{4}$ and $\mathrm{La}_{2}\left(\mathrm{H}_{2} \mathrm{O}\right)_{2}\left(\mathrm{C}_{2} \mathrm{H}_{10} \mathrm{~N}_{2}\right)_{3}\left(\mathrm{SO}_{4}\right)_{6} \cdot 4 \mathrm{H}_{2} \mathrm{O}$, with $3 \mathrm{D}$ and $2 \mathrm{D}$ crystal structures. Journal of Materials Chemistry, 12, 3487-3493. http://dx.doi.org/10.1039/b207212m

[56] Rao, C.N.R., Behera, J.N. and Dan, M. (2006) Organically-templated metal sulfates, selenites and selenates. Chemical Society Reviews, 35, 375-387. http://dx.doi.org/10.1039/b510396g
[57] Nakamoto, K., Fujita, J., Tanaka, S. and Kobayashi, M. (1957) Infrared spectra of metallic complexes. IV. Comparison of the infrared spectra of unidentate and bidentate metallic complexes. Journal of the American Chemical Society, 79, 4904-4908. http://dx.doi.org/10.1021/ja01575a020

[58] Anbalagan, G., Mukundakumari, S., Murugesan, K.S. and Gunasekaran, S. (2007) Preparation, crystal structure and infrared spectroscopy of the new compound rubidium beryllium sulfate dihydrate, $\mathrm{Rb}_{2} \mathrm{Be}\left(\mathrm{SO}_{4}\right)_{2} \cdot 2 \mathrm{H}_{2} \mathrm{O}$. Vibrational Spectroscopy, 44, 226-272.

[59] Wang, T.W., Liu, D.S., Huang, C.C., Sui, Y., Huang, X.H., Chen, J.Z. and You, X.Z. (2010) Syntheses, crystal structures, and magnetic properties of two Mn(II) coordination polymers based on the 5-aminotetrazole ligand: Effect of sources of ligand on construction of topological networks. Crystal Growth and Design, 10, 3429-3435. http://dx.doi.org/10.1021/cg100127w

[60] Bataille, T. and Louër, D. (2004) New linear and layered amine-templated lanthanum sufates. Journal of Solid State Chemistry, 177, 1235-1243. http://dx.doi.org/10.1016/j.jssc.2003.10.031

[61] Zhu, Y., Sun, X., Zhu, D. and Xu, Y. (2009) Solvothermal synthesis, crystal structure and luminescence of the first organic amine templated europium sulfate. Inorganica Chimica Acta, 362, 2565-2568. http://dx.doi.org/10.1016/j.ica.2008.11.015

[62] Xing, Y., Shi, Z., Li, G. and Pang, W. (2003) Hydrothermal synthesis and structure of $\left[\mathrm{C}_{2} \mathrm{~N}_{2} \mathrm{H}_{10}\right]\left[\mathrm{La}_{2}\left(\mathrm{H}_{2} \mathrm{O}\right)_{4}\left(\mathrm{SO}_{4}\right)_{4}\right]$ $2 \mathrm{H}_{2} \mathrm{O}$, a new organically templated rare earth sulfate with a layer structure. Dalton Transactions, 940-943. http://dx.doi.org/10.1039/b211076h

[63] Richardson, F.S. (1982) Terbium(III) and europium(III) ions as luminescent probes and stains for biomolecular systems. Chemical Reviews, 82, 541-552. http://dx.doi.org/10.1021/cr00051a004

[64] Allendorf, M.D., Bauer, C.A., Bhakta, R.K. and Houk, R.J.T. (2009) Luminescent metal-organic frameworks. Chemical Society Reviews, 38, 1330-1352. http://dx.doi.org/10.1039/b802352m 


\section{Supporting Information Available}

Tables S1-S6 show the selected bond lengths and bond angles of the complexes 1, 2, 4, 5, 7, 8; Tables S7-S12 list the hydrogen bonds of the complexes 1, 2, 4, 5, 7, 8; Figures S1-S8 present the PXRD patterns for the simulations based on the X-ray single crystal diffraction and the experimental samples of complexes 1-8; Figures S9 and S10 show the infrared spectra of complexes 1-8, and Figures S11-S16 unfurl the coordination environments of lanthanide atoms, the 2D polyhedron lays, the 2D topology network and the 3D hydrogen bonding network structures in complexes $\mathbf{1}, \mathbf{2}, \mathbf{4}, \mathbf{5}, \mathbf{7}$ and $\mathbf{8}$. Tables of atomic coordinates, isotropic thermal parameters, complete bond distances and angles are deposited in the Cambridge Crystallographic Data Center. Copies of those tables can be obtained free of charge by contacting the Director of the CCDC, 12 Union Road, Cambridge, CB2 1EZ, UK (fax + 44-1223-336033; email deposit@ccdc.cam.ac.uk; http://www.ccdc.cam.ac.uk), and quoting the publication citations and deposition numbers CCDC 904695 (1), 904696 (2), 904697 (3), 904698 (4), 904699 (5), 904700 (6), 904701 (7) and 904702 (8).

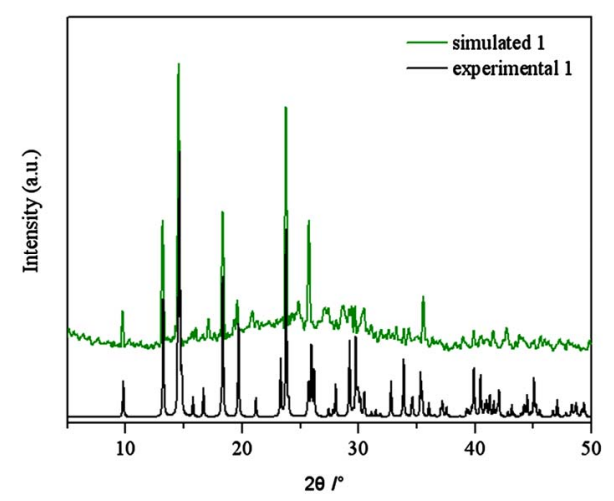

Figure S1. PXRD patterns for the simulated based on the x-ray single crystal diffraction and the experimental samples of complexes 1 .

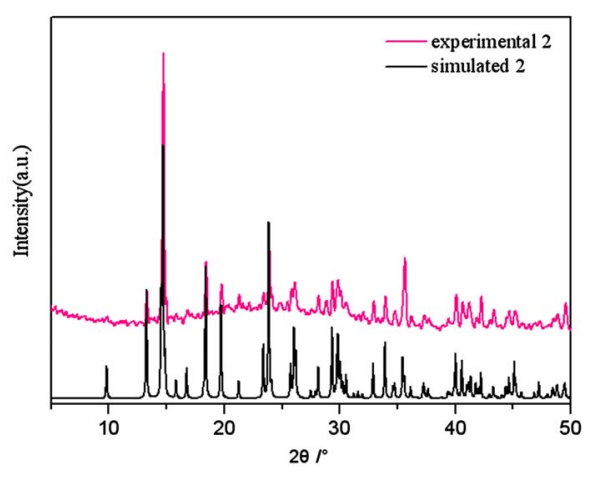

Figure S2. PXRD patterns for the simulated based on the x-ray single crystal diffraction and the experimental samples of complexes 2 .

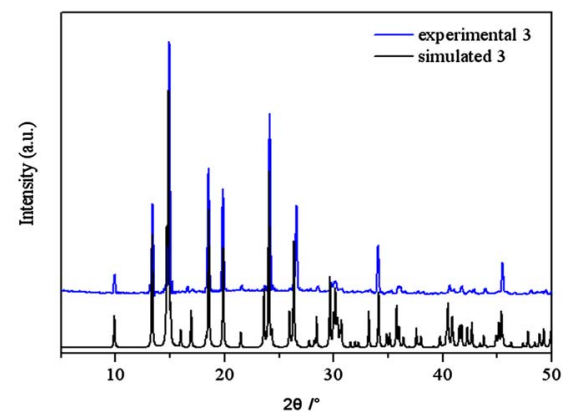

Figure S3. PXRD patterns for the simulated based on the X-ray single crystal diffraction and the experimental samples of complexes 3 .

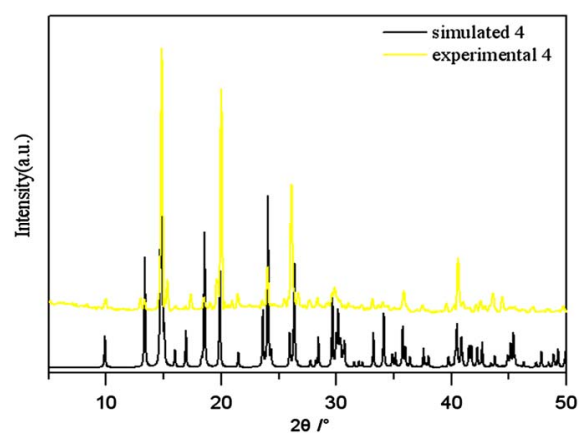

Figure S4. PXRD patterns for the simulated based on the X-ray single crystal diffraction and the experimental samples of complexes 4 .

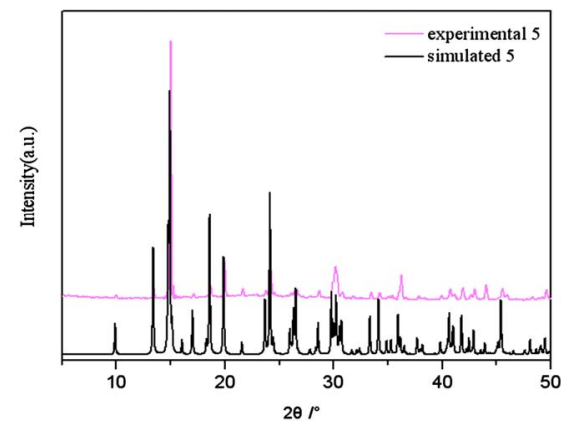

Figure S5. PXRD patterns for the simulated based on the X-ray single crystal diffraction and the experimental samples of complexes 5 .

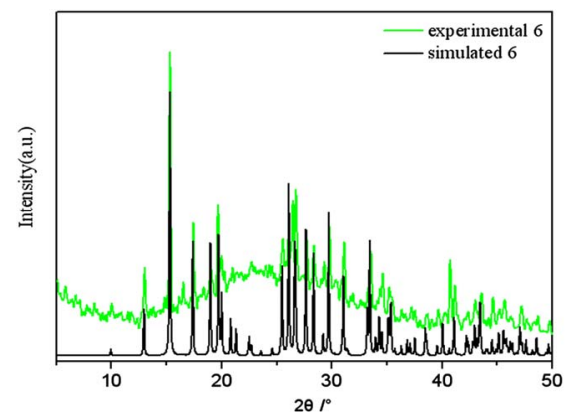

Figure S6. PXRD patterns for the simulated based on the x-ray single crystal diffraction and the experimental samples of complexes 6. 


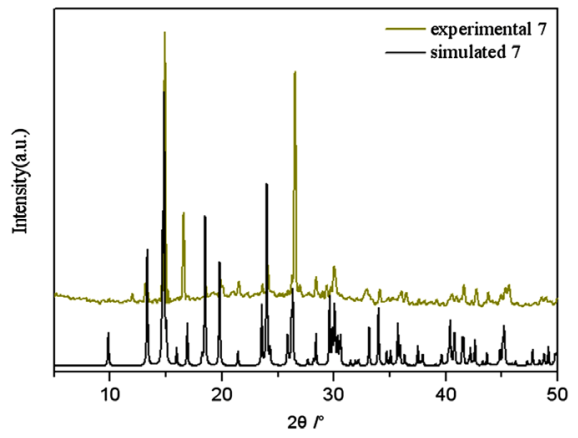

Figure S7. PXRD patterns for the simulated based on the X-ray single crystal diffraction and the experimental samples of complexes 7 .

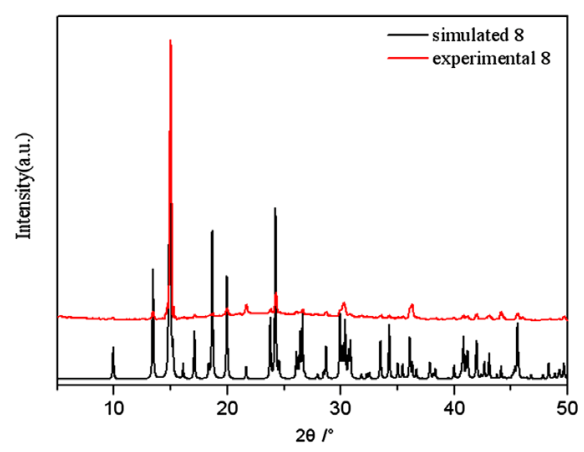

Figure S8. PXRD patterns for the simulated based on the x-ray single crystal diffraction and the experimental samples of complexes $\mathbf{8}$.

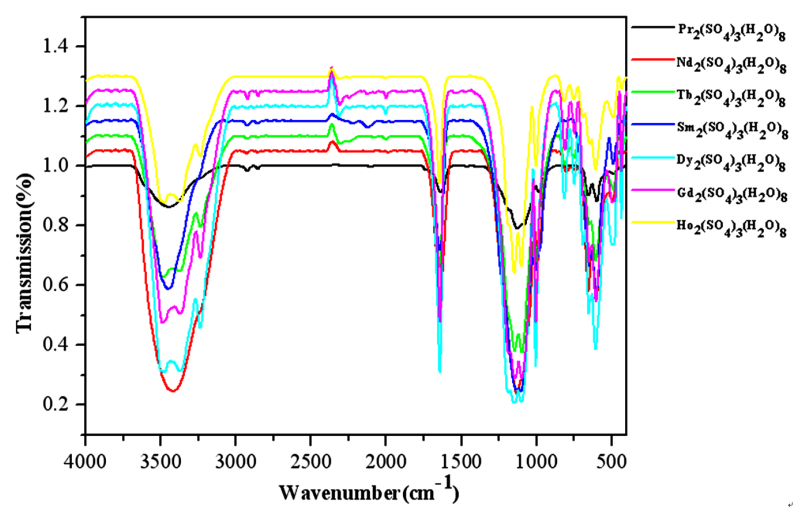

Figure S9. The IR spectra of complexes 1 - 5, 7 - 8.

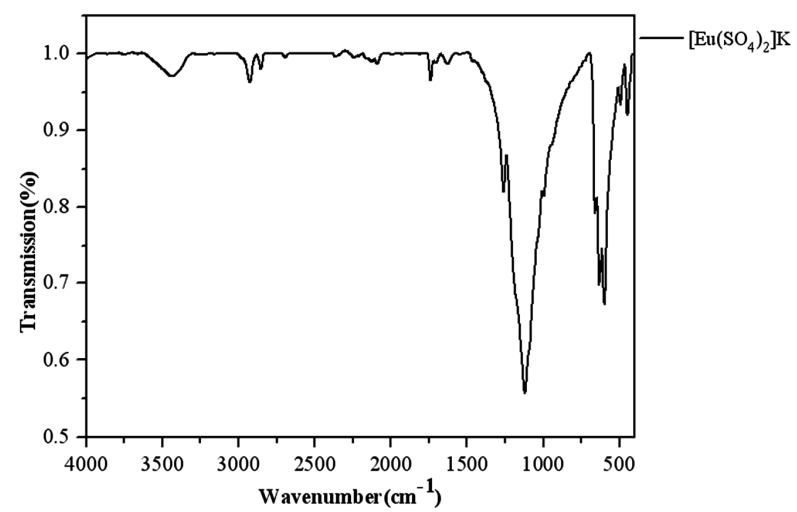

Figure S10. The IR spectra of complex 6.

Table S1. Selected bond distances $(\AA)$ and angles (deg) of complex 1 .

\begin{tabular}{|c|c|c|c|c|c|}
\hline \multicolumn{6}{|c|}{ Bond distances } \\
\hline $\mathrm{Pr}-\mathrm{O}(8)$ & $2.389(3)$ & $\mathrm{Pr}-\mathrm{O}(3)$ & $2.400(3)$ & $\mathrm{Pr}-\mathrm{O}(1)$ & $2.422(3)$ \\
\hline $\mathrm{Pr}-\mathrm{O}(7)$ & $2.447(3)$ & $\mathrm{Pr}-\mathrm{O}(6)$ & $2.459(3)$ & $\mathrm{Pr}-\mathrm{O}(4)$ & $2.518(3)$ \\
\hline $\mathrm{Pr}-\mathrm{O}(5)$ & $2.528(3)$ & $\mathrm{Pr}-\mathrm{O}(2)$ & $2.568(3)$ & & \\
\hline \multicolumn{6}{|c|}{ Bond angles } \\
\hline $\mathrm{O}(8)-\mathrm{Pr}-\mathrm{O}(3)$ & $80.18(11)$ & $\mathrm{O}(8)-\mathrm{Pr}-\mathrm{O}(1)$ & $70.75(10)$ & $\mathrm{O}(3)-\mathrm{Pr}-\mathrm{O}(1)$ & $88.19(11)$ \\
\hline $\mathrm{O}(8)-\mathrm{Pr}-\mathrm{O}(7)$ & $126.00(10)$ & $\mathrm{O}(3)-\mathrm{Pr}-\mathrm{O}(7)$ & $143.31(10)$ & $\mathrm{O}(1)-\mathrm{Pr}-\mathrm{O}(7)$ & $79.26(10)$ \\
\hline $\mathrm{O}(8)-\mathrm{Pr}-\mathrm{O}(6)$ & $79.70(11)$ & $\mathrm{O}(3)-\mathrm{Pr}-\mathrm{O}(6)$ & $147.44(10)$ & $\mathrm{O}(1)-\mathrm{Pr}-\mathrm{O}(6)$ & $108.79(11)$ \\
\hline $\mathrm{O}(7)-\mathrm{Pr}-\mathrm{O}(6)$ & $68.77(10)$ & $\mathrm{O}(8)-\mathrm{Pr}-\mathrm{O}(4)$ & $134.27(11)$ & $\mathrm{O}(3)-\mathrm{Pr}-\mathrm{O}(4)$ & $70.17(11)$ \\
\hline $\mathrm{O}(1)-\mathrm{Pr}-\mathrm{O}(4)$ & $74.21(11)$ & $\mathrm{O}(7)-\mathrm{Pr}-\mathrm{O}(4)$ & $73.26(10)$ & $\mathrm{O}(6)-\mathrm{Pr}-\mathrm{O}(4)$ & $140.32(11)$ \\
\hline $\mathrm{O}(8)-\mathrm{Pr}-\mathrm{O}(5)$ & 139.61(9) & $\mathrm{O}(3)-\mathrm{Pr}-\mathrm{O}(5)$ & $101.70(10)$ & $\mathrm{O}(1)-\mathrm{Pr}-\mathrm{O}(5)$ & $148.96(10)$ \\
\hline $\mathrm{O}(7)-\mathrm{Pr}-\mathrm{O}(5)$ & $75.33(9)$ & $\mathrm{O}(6)-\mathrm{Pr}-\mathrm{O}(5)$ & $78.20(10)$ & $\mathrm{O}(4)-\mathrm{Pr}-\mathrm{O}(5)$ & $81.56(10)$ \\
\hline $\mathrm{O}(8)-\mathrm{Pr}-\mathrm{O}(2)$ & $73.28(9)$ & $\mathrm{O}(3)-\mathrm{Pr}-\mathrm{O}(2)$ & 73.71(9) & $\mathrm{O}(1)-\mathrm{Pr}-\mathrm{O}(2)$ & 141.93(10) \\
\hline $\mathrm{O}(7)-\mathrm{Pr}-\mathrm{O}(2)$ & $133.85(9)$ & $\mathrm{O}(6)-\mathrm{Pr}-\mathrm{O}(2)$ & $76.12(10)$ & $\mathrm{O}(4)-\mathrm{Pr}-\mathrm{O}(2)$ & $126.66(10)$ \\
\hline $\mathrm{O}(5)-\mathrm{Pr}-\mathrm{O}(2)$ & $68.83(9)$ & & & & \\
\hline
\end{tabular}


<smiles>[3H]C[13CH3]</smiles>

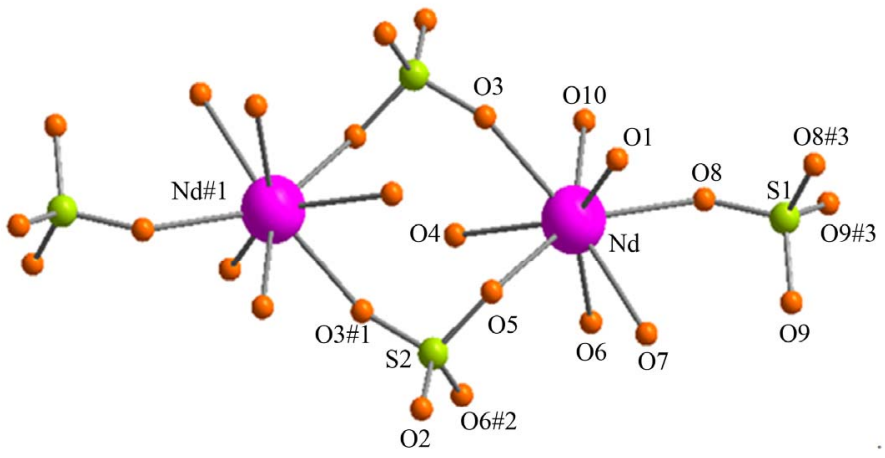

(a)

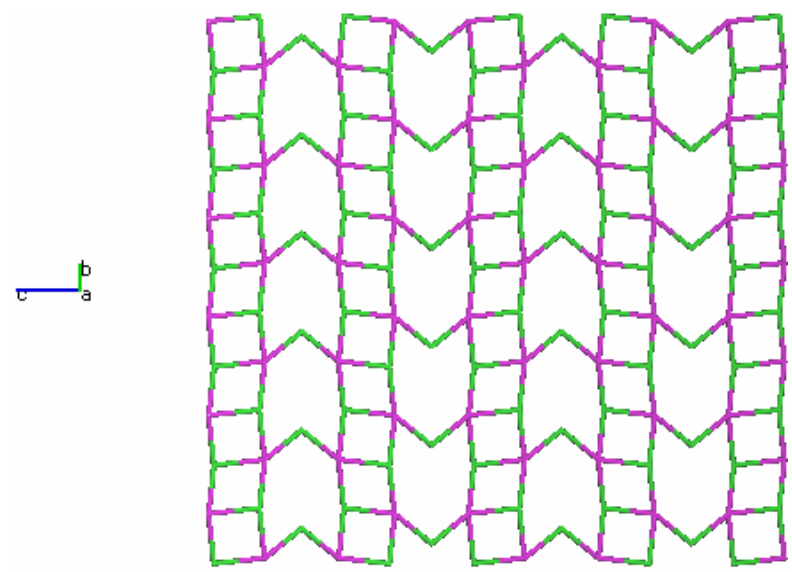

(c)

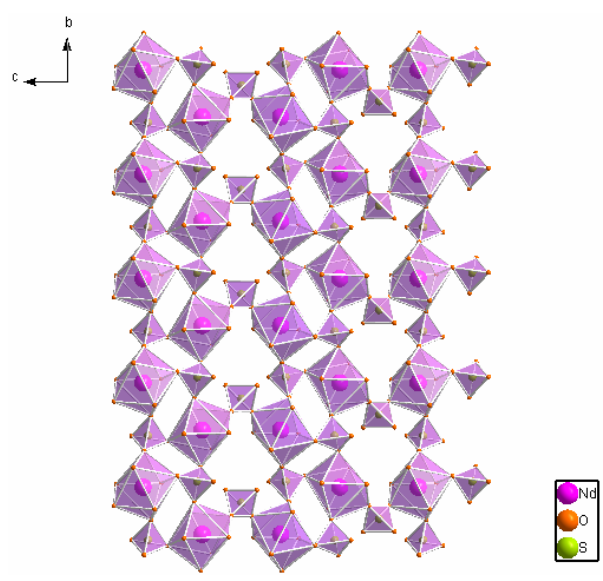

(b)

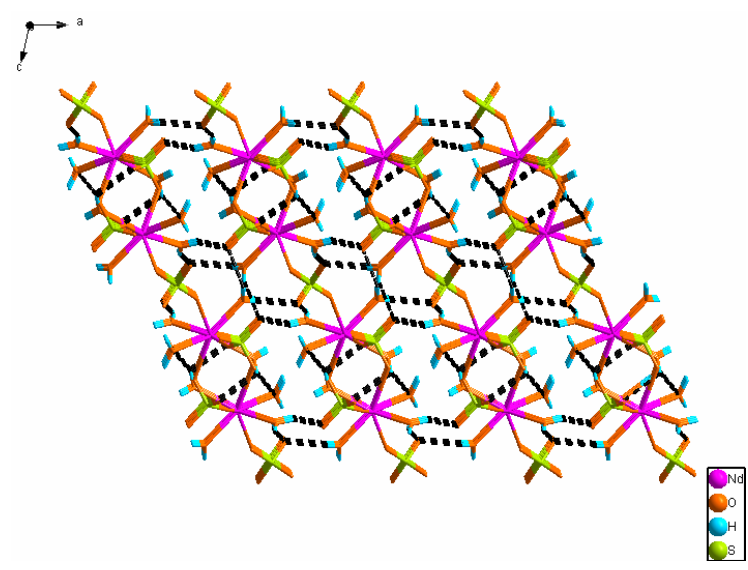

(d)

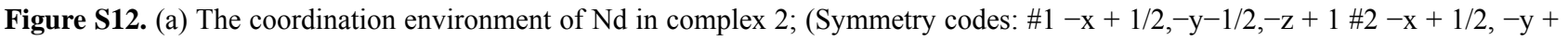
$1 / 2,-z+1 \# 3-x, y,-z+1 / 2$ ) (b) The 2D polyhedron layer in complex 2, viewed along the a-axis; (c) Schematic representation of the $2 \mathrm{D}\left(4^{2} .6 .8^{2} .10\right)_{2}\left(4^{2} .6\right)_{2}(8)$ topology network in complex 1 . Fuchsia, Nd; Lime, $\mathrm{SO}_{4}^{2-}$; (d) A view of the 3D hydrogen bonding network structure of complex 2 (black dotted lines representing hydrogen bonding).

Table S2. Selected bond distances $(\AA)$ and angles (deg) of complex 2.

\begin{tabular}{|c|c|c|c|c|c|}
\hline \multicolumn{6}{|c|}{ Bond distances } \\
\hline $\mathrm{Nd}-\mathrm{O}(8)$ & $2.373(3)$ & $\mathrm{Nd}-\mathrm{O}(6)$ & $2.382(3)$ & $\mathrm{Nd}-\mathrm{O}(10)$ & $2.398(3)$ \\
\hline $\mathrm{Nd}-\mathrm{O}(3)$ & $2.434(3)$ & $\mathrm{Nd}-\mathrm{O}(1)$ & $2.447(3)$ & $\mathrm{Nd}-\mathrm{O}(4)$ & $2.502(3)$ \\
\hline $\mathrm{Nd}-\mathrm{O}(5)$ & $2.510(3)$ & $\mathrm{Nd}-\mathrm{O}(7)$ & $2.555(3)$ & & \\
\hline \multicolumn{6}{|c|}{ Bond angles } \\
\hline $\mathrm{O}(8)-\mathrm{Nd}-\mathrm{O}(6)$ & $80.18(10)$ & $\mathrm{O}(8)-\mathrm{Nd}-\mathrm{O}(10)$ & $70.76(10)$ & $\mathrm{O}(6)-\mathrm{Nd}-\mathrm{O}(10)$ & $88.24(11)$ \\
\hline $\mathrm{O}(8)-\mathrm{Nd}-\mathrm{O}(3)$ & $126.04(10)$ & $\mathrm{O}(8)-\mathrm{Nd}-\mathrm{O}(3)$ & $126.04(10)$ & $\mathrm{O}(6)-\mathrm{Nd}-\mathrm{O}(3)$ & $143.34(8)$ \\
\hline $\mathrm{O}(10)-\mathrm{Nd}-\mathrm{O}(3)$ & $79.30(10)$ & $\mathrm{O}(8)-\mathrm{Nd}-\mathrm{O}(1)$ & $79.80(10)$ & $\mathrm{O}(6)-\mathrm{Nd}-\mathrm{O}(1)$ & $147.43(9)$ \\
\hline $\mathrm{O}(10)-\mathrm{Nd}-\mathrm{O}(1)$ & $108.87(11)$ & $\mathrm{O}(3)-\mathrm{Nd}-\mathrm{O}(1)$ & $68.73(9)$ & $\mathrm{O}(8)-\mathrm{Nd}-\mathrm{O}(4)$ & $134.31(10)$ \\
\hline $\mathrm{O}(6)-\mathrm{Nd}-\mathrm{O}(4)$ & $69.93(9)$ & $\mathrm{O}(10)-\mathrm{Nd}-\mathrm{O}(4)$ & $74.48(11)$ & $\mathrm{O}(3)-\mathrm{Nd}-\mathrm{O}(4)$ & $73.52(9)$ \\
\hline $\mathrm{O}(1)-\mathrm{Nd}-\mathrm{O}(4)$ & $140.43(10)$ & $\mathrm{O}(8)-\mathrm{Nd}-\mathrm{O}(5)$ & $139.84(9)$ & $\mathrm{O}(6)-\mathrm{Nd}-\mathrm{O}(5)$ & $101.20(10)$ \\
\hline $\mathrm{O}(4)-\mathrm{Nd}-\mathrm{O}(5)$ & $80.98(10)$ & $\mathrm{O}(8)-\mathrm{Nd}-\mathrm{O}(7)$ & $73.58(10)$ & $\mathrm{O}(6)-\mathrm{Nd}-\mathrm{O}(7)$ & $73.45(9)$ \\
\hline $\mathrm{O}(10)-\mathrm{Nd}-\mathrm{O}(7)$ & $142.14(10)$ & $\mathrm{O}(3)-\mathrm{Nd}-\mathrm{O}(7)$ & $133.86(9)$ & $\mathrm{O}(1)-\mathrm{Nd}-\mathrm{O}(7)$ & $76.39(9)$ \\
\hline $\mathrm{O}(4)-\mathrm{Nd}-\mathrm{O}(7)$ & $125.91(9)$ & $\mathrm{O}(5)-\mathrm{Nd}-\mathrm{O}(7)$ & $68.64(9)$ & & \\
\hline
\end{tabular}




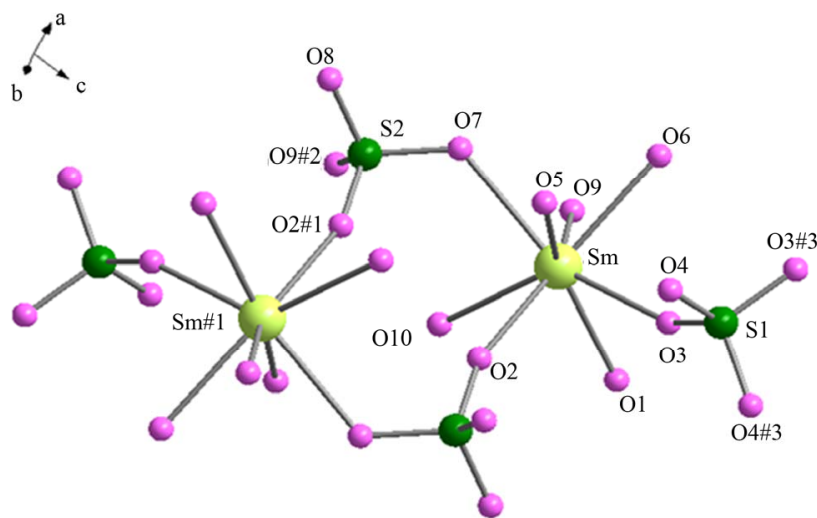

(a)

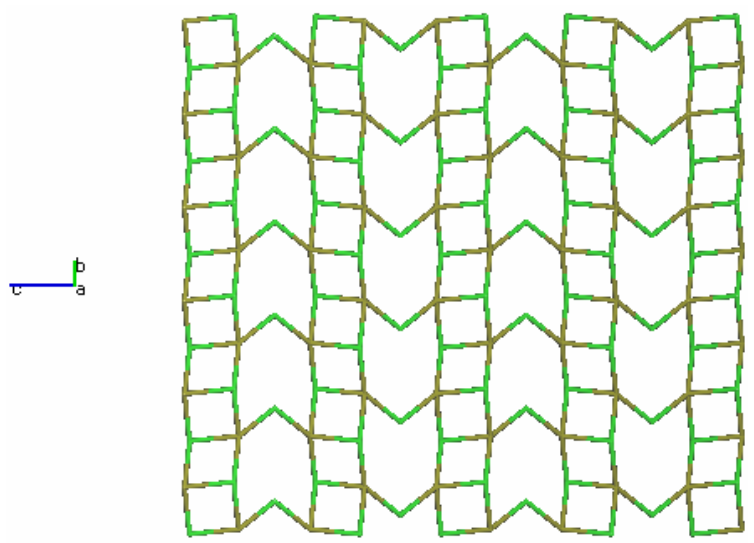

(c)

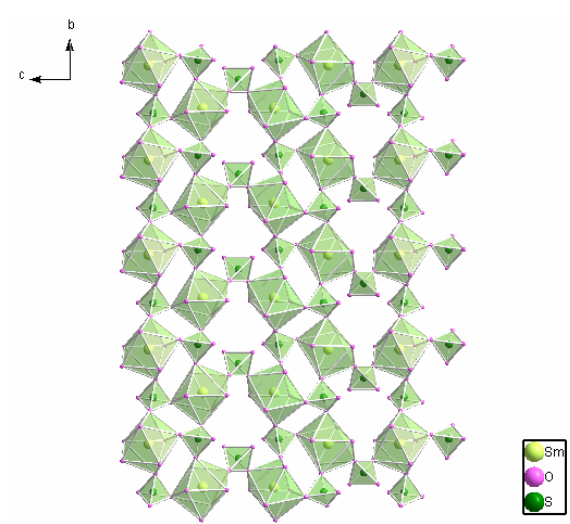

(b)

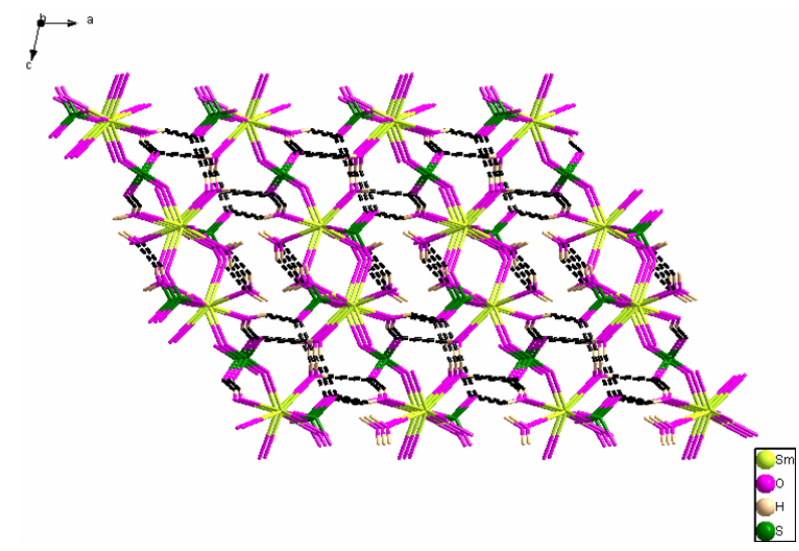

(d)

Figure S13. (a) The coordination environment of Sm in complex 4; (Symmetry codes: $\# 1-x+3 / 2,-y+1 / 2,-z+1 \# 2-x+3 / 2$, $-\mathrm{y}-1 / 2,-\mathrm{z}+1 \# 3-\mathrm{x}+2, \mathrm{y},-\mathrm{z}+3 / 2)$; (b) The 2D polyhedron layer in complex 4, viewed along the a-axis; (c) Schematic representation of the $2 \mathrm{D}\left(4^{2} .6 .8^{2} .10\right)_{2}\left(4^{2} .6\right)_{2}(8)$ topology network in complex 4. Olive, Sm; Lime, $\mathrm{SO}_{4}^{2-}$; (d) A view of the 3D hydrogen bonding network structure of complex 4 (black dotted lines representing hydrogen bonding).

Table S3. Selected bond distances $(\AA)$ and angles (deg) of complex 4.

\begin{tabular}{|c|c|c|c|c|c|}
\hline \multicolumn{6}{|c|}{ Bond distances } \\
\hline $\mathrm{Sm}-\mathrm{O}(3)$ & $2.340(2)$ & $\mathrm{Sm}-\mathrm{O}(2)$ & $2.341(3)$ & $\mathrm{Sm}-\mathrm{O}(1)$ & $2.364(3)$ \\
\hline $\mathrm{Sm}-\mathrm{O}(9)$ & $2.392(2)$ & $\mathrm{Sm}-\mathrm{O}(6)$ & $2.403(3)$ & $\mathrm{Sm}-\mathrm{O}(7)$ & $2.461(2)$ \\
\hline $\mathrm{Sm}-\mathrm{O}(10)$ & $2.467(3)$ & $\mathrm{Sm}-\mathrm{O}(5)$ & $2.514(3)$ & & \\
\hline \multicolumn{6}{|c|}{ Bond angles } \\
\hline $\mathrm{O}(3)-\mathrm{Sm}-\mathrm{O}(2)$ & $80.07(9)$ & $\mathrm{O}(3)-\mathrm{Sm}-\mathrm{O}(1)$ & $70.86(9)$ & $\mathrm{O}(2)-\mathrm{Sm}-\mathrm{O}(1)$ & $88.09(10)$ \\
\hline $\mathrm{O}(3)-\mathrm{Sm}-\mathrm{O}(9)$ & $126.04(8)$ & $\mathrm{O}(2)-\mathrm{Sm}-\mathrm{O}(9)$ & $143.59(8)$ & $\mathrm{O}(1)-\mathrm{Sm}-\mathrm{O}(9)$ & $79.49(9)$ \\
\hline $\mathrm{O}(3)-\mathrm{Sm}-\mathrm{O}(6)$ & $79.75(10)$ & $\mathrm{O}(2)-\mathrm{Sm}-\mathrm{O}(6)$ & $147.10(9)$ & $\mathrm{O}(1)-\mathrm{Sm}-\mathrm{O}(6)$ & $109.26(10)$ \\
\hline $\mathrm{O}(9)-\mathrm{Sm}-\mathrm{O}(6)$ & $68.79(8)$ & $\mathrm{O}(3)-\mathrm{Sm}-\mathrm{O}(7)$ & $140.51(8)$ & $\mathrm{O}(2)-\mathrm{Sm}-\mathrm{O}(7)$ & $100.46(8)$ \\
\hline $\mathrm{O}(1)-\mathrm{Sm}-\mathrm{O}(7)$ & $148.29(9)$ & $\mathrm{O}(9)-\mathrm{Sm}-\mathrm{O}(7)$ & $75.61(8)$ & $\mathrm{O}(6)-\mathrm{Sm}-\mathrm{O}(7)$ & $79.59(9)$ \\
\hline $\mathrm{O}(3)-\mathrm{Sm}-\mathrm{O}(10)$ & $134.49(10)$ & $\mathrm{O}(2)-\mathrm{Sm}-\mathrm{O}(10)$ & $70.19(9)$ & $\mathrm{O}(1)-\mathrm{Sm}-\mathrm{O}(10)$ & $74.41(10)$ \\
\hline $\mathrm{O}(9)-\mathrm{Sm}-\mathrm{O}(10)$ & $73.52(9)$ & $\mathrm{O}(6)-\mathrm{Sm}-\mathrm{O}(10)$ & $140.43(10)$ & $\mathrm{O}(7)-\mathrm{Sm}-\mathrm{O}(10)$ & 79.88(9) \\
\hline $\mathrm{O}(3)-\mathrm{Sm}-\mathrm{O}(5)$ & $73.94(9)$ & $\mathrm{O}(2)-\mathrm{Sm}-\mathrm{O}(5)$ & $73.27(9)$ & $\mathrm{O}(1)-\mathrm{Sm}-\mathrm{O}(5)$ & $142.46(10)$ \\
\hline $\mathrm{O}(9)-\mathrm{Sm}-\mathrm{O}(5)$ & 133.60(9) & $\mathrm{O}(6)-\mathrm{Sm}-\mathrm{O}(5)$ & $76.33(9)$ & $\mathrm{O}(7)-\mathrm{Sm}-\mathrm{O}(5)$ & $68.66(9)$ \\
\hline $\mathrm{O}(10)-\mathrm{Sm}-\mathrm{O}(5)$ & $125.56(9)$ & & & & \\
\hline
\end{tabular}


$y^{b}$

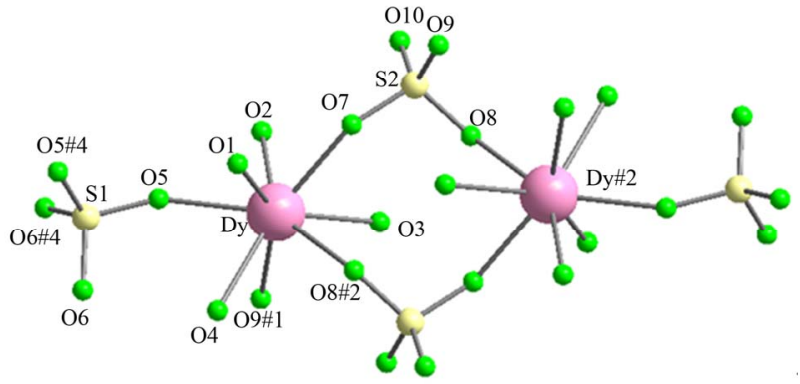

(a)

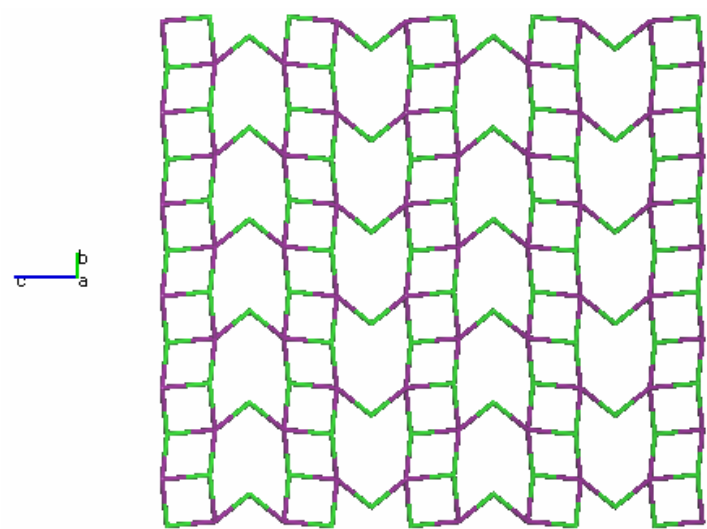

(c)

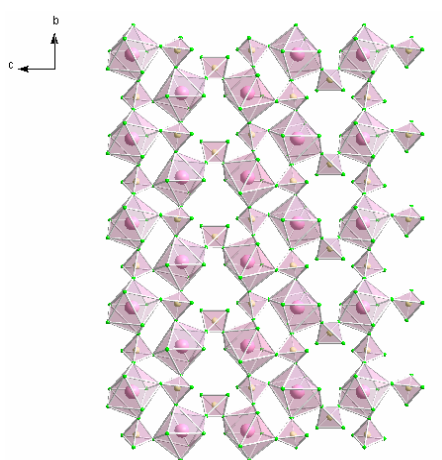

망

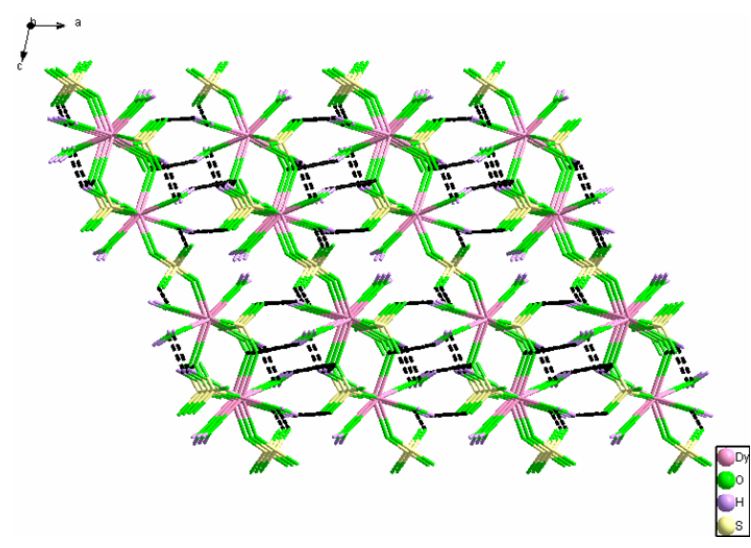

(d)

Figure S14. (a) The coordination environment of Dy in complex 5; (Symmetry codes: $\# 1-x+3 / 2,-y-1 / 2,-z+1 \# 2-x+3 / 2,-y$ $+1 / 2,-z+1 \# 3-x+2, y,-z+3 / 2 \# 41.5-x,-0.5-y, 1-z)$; (b) The 2D polyhedron layer in complex 5, viewed along the a-axis; (c) Schematic representation of the $2 \mathrm{D}\left(4^{2} \cdot 6.8^{2} \cdot 10\right)_{2}\left(4^{2} .6\right)_{2}(8)$ topology network in complex 5. Purple, Dy; Lime, $\mathrm{SO}_{4}^{2-}$; (d) A view of the 3D hydrogen bonding network structure of complex 5 (black dotted lines representing hydrogen bonding).

Table S4. Selected bond distances $(\AA)$ and angles (deg) of complex 5.

\begin{tabular}{|c|c|c|c|c|c|}
\hline \multicolumn{6}{|c|}{ Bond distances } \\
\hline Dy-O(9)\#1 & $2.296(5)$ & Dy-O(2) & $2.308(6)$ & Dy-O(5) & $2.312(4)$ \\
\hline Dy-O(7) & $2.354(5)$ & Dy-O(1) & $2.355(5)$ & $\mathrm{Dy}-\mathrm{O}(8) \# 2$ & $2.411(5)$ \\
\hline Dy-O(3) & $2.436(6)$ & Dy-O(4) & $2.480(5)$ & $\mathrm{O}(8)-\mathrm{Dy} \# 2$ & $2.411(5)$ \\
\hline O(9)-Dy\#3 & $2.296(5)$ & & & & \\
\hline \multicolumn{6}{|c|}{ Bond angles } \\
\hline $\mathrm{O}(9) \# 1-\mathrm{Dy}-\mathrm{O}(2)$ & $88.7(2)$ & $\mathrm{O}(9) \# 1-\mathrm{Dy}-\mathrm{O}(5)$ & $80.05(19)$ & $\mathrm{O}(2)-\mathrm{Dy}-\mathrm{O}(5)$ & $70.50(19)$ \\
\hline O(9)\#1-Dy-O(7) & $144.23(16)$ & $\mathrm{O}(2)-\mathrm{Dy}-\mathrm{O}(7)$ & 79.61(18) & $\mathrm{O}(5)-\mathrm{Dy}-\mathrm{O}(7)$ & $125.79(18)$ \\
\hline $\mathrm{O}(9) \# 1-\mathrm{Dy}-\mathrm{O}(1)$ & $146.58(19)$ & $\mathrm{O}(2)-\mathrm{Dy}-\mathrm{O}(1)$ & $109.0(2)$ & $\mathrm{O}(5)-\mathrm{Dy}-\mathrm{O}(1)$ & $79.7(2)$ \\
\hline $\mathrm{O}(7)-\mathrm{Dy}-\mathrm{O}(1)$ & $68.61(17)$ & $\mathrm{O}(9) \# 1-\mathrm{Dy}-\mathrm{O}(8) \# 2$ & $99.55(19)$ & $\mathrm{O}(2)-\mathrm{Dy}-\mathrm{O}(8) \# 2$ & $147.6(2)$ \\
\hline $\mathrm{O}(5)-\mathrm{Dy}-\mathrm{O}(8) \# 2$ & $141.66(17)$ & $\mathrm{O}(7)-\mathrm{Dy}-\mathrm{O}(8) \# 2$ & $75.47(19)$ & $\mathrm{O}(1)-\mathrm{Dy}-\mathrm{O}(8) \# 2$ & $80.80(19)$ \\
\hline $\mathrm{O}(9) \# 1-\mathrm{Dy}-\mathrm{O}(3)$ & $70.29(18)$ & $\mathrm{O}(2)-\mathrm{Dy}-\mathrm{O}(3)$ & $74.6(2)$ & $\mathrm{O}(5)-\mathrm{Dy}-\mathrm{O}(3)$ & $134.18(19)$ \\
\hline $\mathrm{O}(7)-\mathrm{Dy}-\mathrm{O}(3)$ & $74.02(16)$ & $\mathrm{O}(1)-\mathrm{Dy}-\mathrm{O}(3)$ & $140.80(18)$ & $\mathrm{O}(8) \# 2-\mathrm{Dy}-\mathrm{O}(3)$ & $78.82(19)$ \\
\hline $\mathrm{O}(9) \# 1-\mathrm{Dy}-\mathrm{O}(4)$ & $73.05(18)$ & $\mathrm{O}(2)-\mathrm{Dy}-\mathrm{O}(4)$ & $143.05(18)$ & $\mathrm{O}(5)-\mathrm{Dy}-\mathrm{O}(4)$ & $74.78(15)$ \\
\hline $\mathrm{O}(7)-\mathrm{Dy}-\mathrm{O}(4)$ & $132.84(16)$ & $\mathrm{O}(1)-\mathrm{Dy}-\mathrm{O}(4)$ & $76.16(18)$ & $\mathrm{O}(8) \# 2-\mathrm{Dy}-\mathrm{O}(4)$ & $68.67(17)$ \\
\hline $\mathrm{O}(3)-\mathrm{Dy}-\mathrm{O}(4)$ & $125.17(17)$ & & & & \\
\hline
\end{tabular}

*Symmetry transformations used to generate equivalent atoms: ${ }^{\#} 1 \mathrm{x}, \mathrm{y}-1, \mathrm{z} \# 2-\mathrm{x}+1 / 2,-\mathrm{y}+3 / 2,-\mathrm{z} \# 3 \mathrm{x}, \mathrm{y}+1, \mathrm{z}$. 


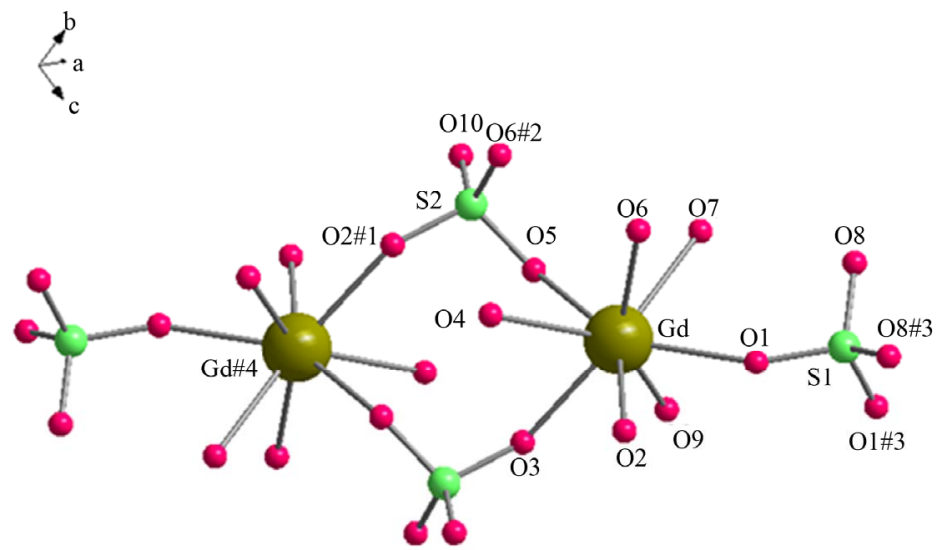

(a)

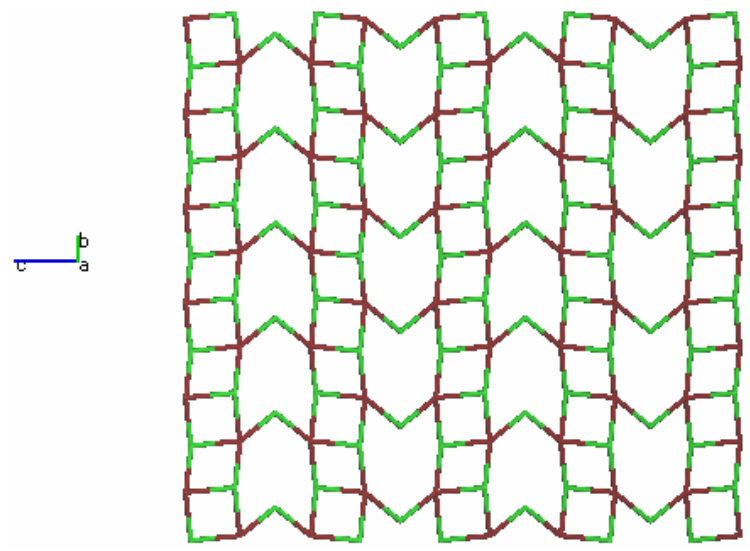

(c)

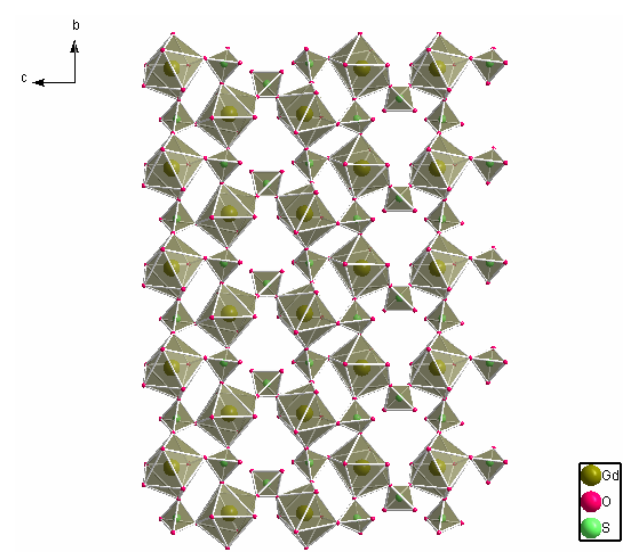

(b)

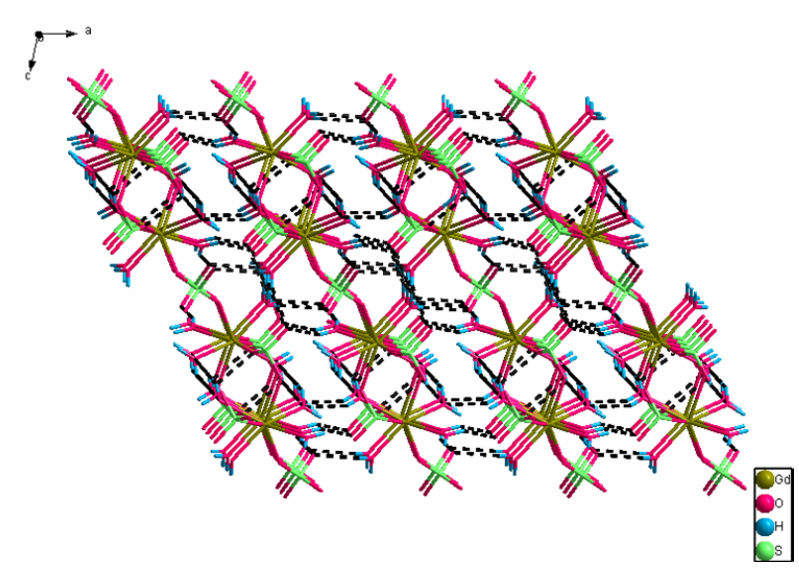

(d)

Figure S15. (a) The coordination environment of Gd in complex 7; (Symmetry codes: \#1 $-x+3 / 2,-y-1 / 2,-z+1 \# 2-x+3 / 2,-y+$ $1 / 2,-z+1 \# 3-x+2, y,-z+3 / 2 \# 41.5-x,-0.5-y, 1-z) ;(b)$ The 2D polyhedron layer in complex 7, viewed along the a-axis; (c) Schematic representation of the $2 \mathrm{D}\left(4^{2} .6 .8^{2} .10\right)_{2}\left(4^{2} .6\right)_{2}(8)$ topology network in complex 7. Maroon, Gd; Lime, $\mathrm{SO}_{4}^{2-}$; (d) A view of the $3 \mathrm{D}$ hydrogen bonding network structure of complex 7 (black dotted lines representing hydrogen bonding).

Table S5. Selected bond distances $(\AA)$ and angles (deg) of complex 7.

\begin{tabular}{|c|c|c|c|c|c|}
\hline \multicolumn{6}{|c|}{ Bond distances } \\
\hline Gd-O(6) & $2.331(4)$ & Gd-O(1) & $2.336(4)$ & Gd-O(2) & $2.355(6)$ \\
\hline Gd-O(3) & $2.385(4)$ & Gd-O(9) & $2.389(4)$ & Gd-O(5) & $2.455(4)$ \\
\hline Gd-O(4) & $2.470(6)$ & Gd-O(7) & $2.513(4)$ & & \\
\hline \multicolumn{6}{|c|}{ Bond angles } \\
\hline $\mathrm{O}(6)-\mathrm{Gd}-\mathrm{O}(1)$ & $80.00(16)$ & $\mathrm{O}(6)-\mathrm{Gd}-\mathrm{O}(2)$ & $88.33(17)$ & $\mathrm{O}(1)-\mathrm{Gd}-\mathrm{O}(2)$ & $70.74(17)$ \\
\hline $\mathrm{O}(6)-\mathrm{Gd}-\mathrm{O}(3)$ & $143.93(14)$ & $\mathrm{O}(1)-\mathrm{Gd}-\mathrm{O}(3)$ & $125.97(16)$ & $\mathrm{O}(2)-\mathrm{Gd}-\mathrm{O}(3)$ & $79.59(15)$ \\
\hline $\mathrm{O}(6)-\mathrm{Gd}-\mathrm{O}(9)$ & $146.81(16)$ & $\mathrm{O}(1)-\mathrm{Gd}-\mathrm{O}(9)$ & $79.30(17)$ & $\mathrm{O}(2)-\mathrm{Gd}-\mathrm{O}(9)$ & $108.75(19)$ \\
\hline $\mathrm{O}(3)-\mathrm{Gd}-\mathrm{O}(9)$ & $68.78(15)$ & $\mathrm{O}(6)-\mathrm{Gd}-\mathrm{O}(5)$ & $100.05(16)$ & $\mathrm{O}(1)-\mathrm{Gd}-\mathrm{O}(5)$ & $141.04(15)$ \\
\hline $\mathrm{O}(2)-\mathrm{Gd}-\mathrm{O}(5)$ & 147.93(17) & $\mathrm{O}(3)-\mathrm{Gd}-\mathrm{O}(5)$ & $75.51(15)$ & $\mathrm{O}(9)-\mathrm{Gd}-\mathrm{O}(5)$ & $80.66(16)$ \\
\hline $\mathrm{O}(6)-\mathrm{Gd}-\mathrm{O}(4)$ & $70.33(14)$ & $\mathrm{O}(1)-\mathrm{Gd}-\mathrm{O}(4)$ & $134.41(17)$ & $\mathrm{O}(2)-\mathrm{Gd}-\mathrm{O}(4)$ & $74.5(2)$ \\
\hline $\mathrm{O}(3)-\mathrm{Gd}-\mathrm{O}(4)$ & $73.70(14)$ & $\mathrm{O}(9)-\mathrm{Gd}-\mathrm{O}(4)$ & $140.78(15)$ & $\mathrm{O}(5)-\mathrm{Gd}-\mathrm{O}(4)$ & 79.33(17) \\
\hline $\mathrm{O}(6)-\mathrm{Gd}-\mathrm{O}(7)$ & $73.22(15)$ & $\mathrm{O}(1)-\mathrm{Gd}-\mathrm{O}(7)$ & $74.02(14)$ & $\mathrm{O}(2)-\mathrm{Gd}-\mathrm{O}(7)$ & $142.52(16)$ \\
\hline $\mathrm{O}(3)-\mathrm{Gd}-\mathrm{O}(7)$ & $133.30(15)$ & $\mathrm{O}(9)-\mathrm{Gd}-\mathrm{O}(7)$ & $76.29(16)$ & $\mathrm{O}(5)-\mathrm{Gd}-\mathrm{O}(7)$ & $68.92(15)$ \\
\hline $\mathrm{O}(4)-\mathrm{Gd}-\mathrm{O}(7)$ & $125.65(15)$ & & & & \\
\hline
\end{tabular}




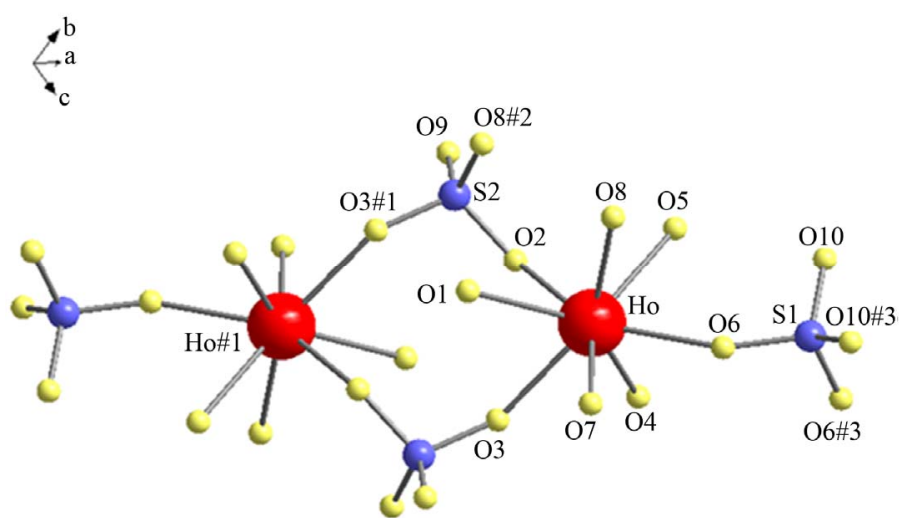

(a)

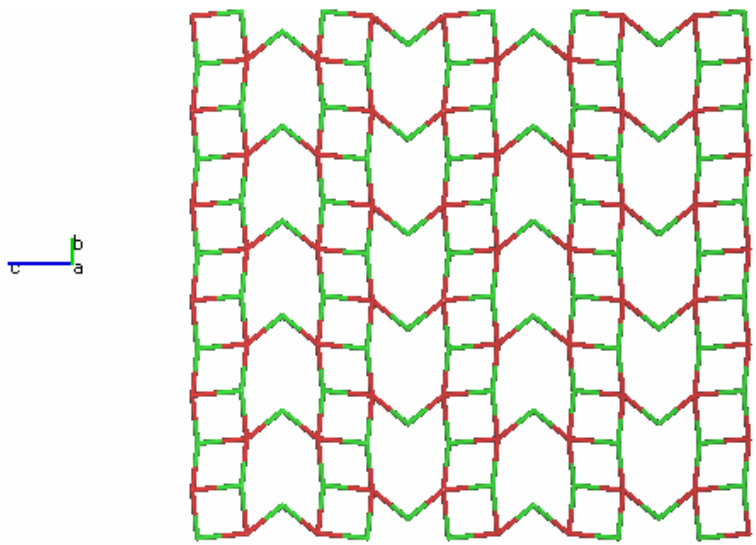

(c)

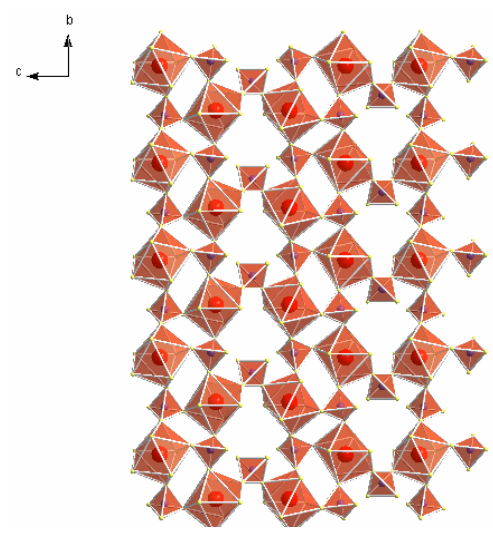

(b)
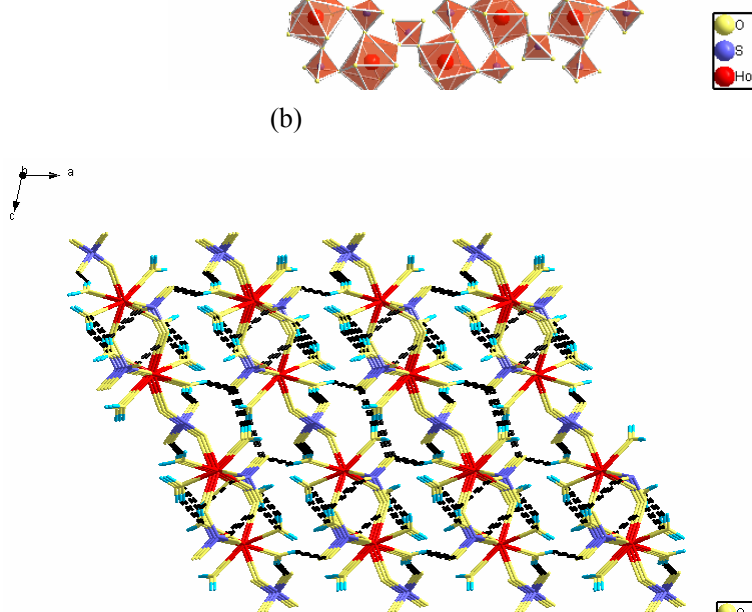

(d)

Figure S16. (a) The coordination environment of Ho in complex 8; (Symmetry codes: $\# 1-x+3 / 2,-y-1 / 2,-z \# 2-x+3 / 2,-y+$ $1 / 2,-\mathrm{z} \# 3-\mathrm{x}+2, \mathrm{y},-\mathrm{z}+1 / 2)$; (b) The 2D polyhedron layer in complex 8, viewed along the a-axis; (c) Schematic representation of the $2 \mathrm{D}\left(4^{2} .6 .8^{2} .10\right)_{2}\left(4^{2} .6\right)_{2}(8)$ topology network in complex 8 . Red, Ho; Lime, $\mathrm{SO}_{4}^{2-}$; (d) A view of the 3D hydrogen bonding network structure of complex 8 (black dotted lines representing hydrogen bonding).

Table S6. Selected bond distances $(\AA)$ and angles (deg) of complex 8 .

\begin{tabular}{|c|c|c|c|c|c|}
\hline \multicolumn{6}{|c|}{ Bond distances } \\
\hline $\mathrm{O}(1)-\mathrm{Ho}$ & $2.429(6)$ & $\mathrm{O}(2)-\mathrm{Ho}$ & $2.392(5)$ & $\mathrm{O}(3)-\mathrm{Ho}$ & $2.350(5)$ \\
\hline $\mathrm{O}(4)-\mathrm{Ho}$ & $2.339(5)$ & $\mathrm{O}(5)-\mathrm{Ho}$ & $2.461(5)$ & $\mathrm{O}(6)-\mathrm{Ho}$ & $2.299(4)$ \\
\hline $\mathrm{O}(7)-\mathrm{Ho}$ & $2.308(6)$ & $\mathrm{O}(8)-\mathrm{Ho}$ & $2.285(5)$ & & \\
\hline \multicolumn{6}{|c|}{ Bond angles } \\
\hline $\mathrm{O}(8)-\mathrm{Ho}-\mathrm{O}(6)$ & 79.99(19) & $\mathrm{O}(8)-\mathrm{Ho}-\mathrm{O}(7)$ & $88.7(2)$ & $\mathrm{O}(6)-\mathrm{Ho}-\mathrm{O}(7)$ & $70.89(19)$ \\
\hline $\mathrm{O}(8)-\mathrm{Ho}-\mathrm{O}(4)$ & $146.68(19)$ & $\mathrm{O}(6)-\mathrm{Ho}-\mathrm{O}(4)$ & $79.7(2)$ & $\mathrm{O}(7)-\mathrm{Ho}-\mathrm{O}(4)$ & 109.1(2) \\
\hline $\mathrm{O}(8)-\mathrm{Ho}-\mathrm{O}(3)$ & $144.47(16)$ & $\mathrm{O}(6)-\mathrm{Ho}-\mathrm{O}(3)$ & $125.62(18)$ & $\mathrm{O}(7)-\mathrm{Ho}-\mathrm{O}(3)$ & $79.39(18)$ \\
\hline $\mathrm{O}(4)-\mathrm{Ho}-\mathrm{O}(3)$ & $68.30(18)$ & $\mathrm{O}(8)-\mathrm{Ho}-\mathrm{O}(2)$ & $99.48(18)$ & $\mathrm{O}(6)-\mathrm{Ho}-\mathrm{O}(2)$ & $141.66(17)$ \\
\hline $\mathrm{O}(7)-\mathrm{Ho}-\mathrm{O}(2)$ & $147.2(2)$ & $\mathrm{O}(4)-\mathrm{Ho}-\mathrm{O}(2)$ & $80.90(19)$ & $\mathrm{O}(3)-\mathrm{Ho}-\mathrm{O}(2)$ & $75.64(18)$ \\
\hline $\mathrm{O}(8)-\mathrm{Ho}-\mathrm{O}(1)$ & $70.27(17)$ & $\mathrm{O}(6)-\mathrm{Ho}-\mathrm{O}(1)$ & $134.10(19)$ & $\mathrm{O}(7)-\mathrm{Ho}-\mathrm{O}(1)$ & $74.2(2)$ \\
\hline $\mathrm{O}(4)-\mathrm{Ho}-\mathrm{O}(1)$ & $140.77(18)$ & $\mathrm{O}(3)-\mathrm{Ho}-\mathrm{O}(1)$ & $74.28(16)$ & $\mathrm{O}(2)-\mathrm{Ho}-\mathrm{O}(1)$ & 78.83(19) \\
\hline $\mathrm{O}(8)-\mathrm{Ho}-\mathrm{O}(5)$ & $72.90(17)$ & $\mathrm{O}(6)-\mathrm{Ho}-\mathrm{O}(5)$ & $74.73(15)$ & $\mathrm{O}(7)-\mathrm{Ho}-\mathrm{O}(5)$ & $143.30(18)$ \\
\hline $\mathrm{O}(4)-\mathrm{Ho}-\mathrm{O}(5)$ & $76.41(18)$ & $\mathrm{O}(3)-\mathrm{Ho}-\mathrm{O}(5)$ & 132.91(16) & $\mathrm{O}(2)-\mathrm{Ho}-\mathrm{O}(5)$ & $68.70(17)$ \\
\hline $\mathrm{O}(1)-\mathrm{Ho}-\mathrm{O}(5)$ & $125.10(17)$ & & & & \\
\hline
\end{tabular}


Table S7. Hydrogen bonds of complex $\mathbf{1} / \AA$ and symmetry codes: j: $1 / 2+\mathrm{x}, 1 / 2+\mathrm{y}, \mathrm{z} ; \mathrm{k}: 1 / 2-\mathrm{x}, 1 / 2+\mathrm{y}, 1 / 2-\mathrm{z} ; \mathrm{e}: 1 / 2-\mathrm{x}, 3 / 2-\mathrm{y}$, $1-\mathrm{z} ; \mathrm{d}: 1 / 2-\mathrm{x}, 1 / 2-\mathrm{y}, 1-\mathrm{z} ; \mathrm{b}: \mathrm{x}, 1+\mathrm{y}, \mathrm{z} ; \mathrm{m}:-1 / 2+\mathrm{x}, 1 / 2+\mathrm{y}, \mathrm{z}$.

\begin{tabular}{|c|c|c|c|c|}
\hline $\mathrm{D}-\mathrm{H} \cdots \mathrm{A}$ & D-H & $\mathrm{H} \cdots \mathrm{A}$ & $\mathrm{D} \cdots \mathrm{A}$ & $<\mathrm{D}-\mathrm{H} \cdots \mathrm{A}$ \\
\hline O1-H1A $\cdots{ }^{\prime} 9^{j}$ & 0.9300 & 2.0172 & 2.8090 & 141.99 \\
\hline O1-H1B $\cdots$ O10 & 0.9300 & 1.9459 & 2.7623 & 145.38 \\
\hline $\mathrm{O} 4-\mathrm{H} 4 \mathrm{~A} \cdots \mathrm{O}^{\mathrm{e}}$ & 0.8566 & 2.0407 & 2.7847 & 144.79 \\
\hline $\mathrm{O} 4-\mathrm{H} 4 \mathrm{~B} \cdots \mathrm{O} 2^{\mathrm{d}}$ & 0.7855 & 2.1451 & 2.9182 & 168.11 \\
\hline O6-H6A $\cdots 9^{b}$ & 0.8999 & 1.9888 & 2.8320 & 155.40 \\
\hline O6-H6B $\cdots \mathrm{O} 10^{\mathrm{m}}$ & 0.9000 & 1.8867 & 2.7371 & 156.84 \\
\hline
\end{tabular}

Table S8. Hydrogen bonds of complex 2/Å and symmetry codes: $\mathrm{g}$ : $1 / 2+\mathrm{x}, 1 / 2+\mathrm{y}, \mathrm{z} ; \mathrm{a}: \mathrm{x},-1+\mathrm{y}, \mathrm{z} ; \mathrm{e}: 1 / 2-\mathrm{x}, 3 / 2-\mathrm{y},-\mathrm{z}$; d: $1 / 2-$ $\mathrm{x}, 1 / 2-\mathrm{y},-\mathrm{z} ; \mathrm{h}: 1 / 2-\mathrm{x}, 1 / 2+\mathrm{y}, 1 / 2-\mathrm{z} ; \mathrm{i}:-1 / 2+\mathrm{x},-1 / 2+\mathrm{y}, \mathrm{z}$.

\begin{tabular}{|c|c|c|c|c|}
\hline $\mathrm{D}-\mathrm{H} \cdots \mathrm{A}$ & D-H & $\mathrm{H} \cdots \mathrm{A}$ & $\mathrm{D} \cdots \mathrm{A}$ & $<\mathrm{D}-\mathrm{H} \cdots \mathrm{A}$ \\
\hline $\mathrm{O} 1-\mathrm{H} 1 \mathrm{~A} \cdots \mathrm{O} 2^{\mathrm{g}}$ & 0.8999 & 1.8819 & 2.7288 & 156.03 \\
\hline $\mathrm{O} 1-\mathrm{H} 1 \mathrm{~B} \cdots \mathrm{O} 9^{\mathrm{a}}$ & 0.9000 & 1.9757 & 2.8210 & 155.82 \\
\hline $\mathrm{O} 4-\mathrm{H} 4 \mathrm{~A} \cdots \mathrm{O} 7^{\mathrm{e}}$ & 0.9001 & 2.0859 & 2.9144 & 152.57 \\
\hline $\mathrm{O} 4-\mathrm{H} 4 \mathrm{~B} \cdots \mathrm{O} 5^{\mathrm{d}}$ & 0.7370 & 2.1825 & 2.7968 & 141.45 \\
\hline $\mathrm{O} 10-\mathrm{H} 10 \mathrm{~A} \cdots \mathrm{O} 2^{\mathrm{h}}$ & 0.9001 & 2.1579 & 2.7649 & 124.11 \\
\hline O10-H10B $\cdots \mathrm{O}^{\mathrm{i}}$ & 0.9000 & 2.2344 & 2.8173 & 122.05 \\
\hline
\end{tabular}

Table S9. Hydrogen bonds of complex $4 / \AA$ and symmetry codes: $\mathrm{k}: 1 / 2-\mathrm{x}, 1 / 2+\mathrm{y}, 1 / 2-\mathrm{z} ; \mathrm{j}:-1 / 2+\mathrm{x}, 1 / 2+\mathrm{y}, \mathrm{z} ; \mathrm{m}: 1 / 2+\mathrm{x}, 1 / 2+$ $\mathrm{y}, \mathrm{z} ; \mathrm{b}: \mathrm{x}, 1+\mathrm{y}, \mathrm{z} ; \mathrm{d}: 1 / 2-\mathrm{x}, 1 / 2-\mathrm{y},-\mathrm{z} ; \mathrm{e}: 1 / 2-\mathrm{x}, 3 / 2-\mathrm{y},-\mathrm{z}$.

\begin{tabular}{|c|c|c|c|c|}
\hline $\mathrm{D}-\mathrm{H} \cdots \mathrm{A}$ & D-H & $\mathrm{H} \cdots \mathrm{A}$ & $\mathrm{D} \cdots \mathrm{A}$ & $<\mathrm{D}-\mathrm{H} \cdots \mathrm{A}$ \\
\hline $\mathrm{O} 1-\mathrm{H} 1 \mathrm{~A} \cdots \mathrm{O} 8^{\mathrm{k}}$ & 0.8999 & 2.1331 & 2.7463 & 124.64 \\
\hline $\mathrm{O} 1-\mathrm{H} 1 \mathrm{~B} \cdots \mathrm{O} 4^{\mathrm{j}}$ & 0.8998 & 2.2262 & 2.8012 & 121.30 \\
\hline O6-H6A $\cdots{ }^{\mathrm{O}} 8^{\mathrm{m}}$ & 0.8999 & 1.8712 & 2.7129 & 154.84 \\
\hline O6-H6B $\cdots O 4^{b}$ & 0.9000 & 1.9653 & 2.8127 & 156.28 \\
\hline $\mathrm{O} 10-\mathrm{H} 10 \mathrm{~A} \cdots \mathrm{O}^{\mathrm{d}}$ & 0.7541 & 2.1869 & 2.9253 & 166.44 \\
\hline $\mathrm{O} 10-\mathrm{H} 10 \mathrm{~B} \cdots \mathrm{O}^{\mathrm{e}}$ & 0.7326 & 2.1383 & 2.7803 & 146.79 \\
\hline
\end{tabular}

Table S10. Hydrogen bonds of complex 5/A and symmetry codes: a: $x,-1+y, z ; f: 1 / 2+x,-1 / 2+y, z ; d: 1 / 2-x, 3 / 2-y,-z ;$ e: $1 / 2-x, 1 / 2-y,-z ; j: 1-x, 1-y,-z$.

\begin{tabular}{ccccc}
\hline D-H $\cdots \mathrm{A}$ & $\mathrm{D}-\mathrm{H}$ & $\mathrm{H} \cdots \mathrm{A}$ & $\mathrm{D} \cdots \mathrm{A}$ & $<\mathrm{D}-\mathrm{H} \cdots \mathrm{A}$ \\
\hline O1-H1A $\cdots \mathrm{O}^{\mathrm{a}}$ & 0.9000 & 2.0531 & 2.8321 & 144.17 \\
O1-H1B $\cdots \mathrm{O} 10^{\mathrm{f}}$ & 0.9000 & 1.8650 & 2.7259 & 159.41 \\
O3-H3A $\cdots \mathrm{O}^{\mathrm{d}}$ & 0.9000 & 1.9752 & 2.7901 & 149.82 \\
O3-H3B $\cdots \mathrm{O}^{\mathrm{e}}$ & 0.9000 & 2.1834 & 2.9650 & 144.85 \\
O4-H4A $\cdots \mathrm{O}^{\mathrm{j}}$ & 0.8999 & 2.1893 & 3.0411 & 157.70 \\
\hline
\end{tabular}


Table S11. Hydrogen bonds of complex $7 / \AA$ and symmetry codes: $\mathrm{h}: 1 / 2-\mathrm{x},-1 / 2+\mathrm{y}, 1 / 2-\mathrm{z} ; \mathrm{i}:-1 / 2+\mathrm{x}, 1 / 2+\mathrm{y}, \mathrm{z} ; \mathrm{e}: 1 / 2-\mathrm{x}, 1 / 2$ $-\mathrm{y},-\mathrm{z} ; \mathrm{d}: 1 / 2-\mathrm{x}, 3 / 2-\mathrm{y},-\mathrm{z} ; \mathrm{g}: 1 / 2+\mathrm{x},-1 / 2+\mathrm{y}, \mathrm{z} ; \mathrm{a}: \mathrm{x},-1+\mathrm{y}, \mathrm{z}$.

\begin{tabular}{|c|c|c|c|c|}
\hline $\mathrm{D}-\mathrm{H} \cdots \mathrm{A}$ & D-H & $\mathrm{H} \cdots \mathrm{A}$ & $\mathrm{D} \cdots \mathrm{A}$ & $<\mathrm{D}-\mathrm{H} \cdots \mathrm{A}$ \\
\hline $\mathrm{O} 2-\mathrm{H} 2 \mathrm{~A} \cdots \mathrm{O} 10^{\mathrm{h}}$ & 0.9000 & 2.1245 & 2.7551 & 126.37 \\
\hline $\mathrm{O} 2-\mathrm{H} 2 \mathrm{~B} \cdots \mathrm{O} 8^{\mathrm{i}}$ & 0.9000 & 2.2537 & 2.8251 & 121.04 \\
\hline $\mathrm{O} 4-\mathrm{H} 4 \mathrm{~A} \cdots \mathrm{O}^{\mathrm{e}}$ & 0.8999 & 2.1307 & 2.9604 & 152.91 \\
\hline $\mathrm{O} 4-\mathrm{H} 4 \mathrm{~B} \cdots \mathrm{O} 5^{\mathrm{d}}$ & 0.9784 & 2.0107 & 2.7882 & 134.83 \\
\hline $\mathrm{O} 7-\mathrm{H} 7 \mathrm{~A} \cdots \mathrm{O} 4^{\mathrm{e}}$ & 0.9000 & 2.1508 & 2.9604 & 149.26 \\
\hline O9-H9A $\cdots$ O10 & 0.9001 & 1.8892 & 2.7313 & 154.94 \\
\hline O9-H9B $\cdots{ }^{a} 8^{a}$ & 0.9000 & 1.9902 & 2.8360 & 155.98 \\
\hline
\end{tabular}

Table S12. Hydrogen bonds of complex $8 / \AA ̊$ and symmetry codes: c: 1/2-x, 3/2-y, $-\mathrm{z} ; \mathrm{h}: 1-\mathrm{x}, 1-\mathrm{y},-\mathrm{z} ; \mathrm{k}: \mathrm{x},-1+\mathrm{y}, \mathrm{z} ; 1: \mathrm{x}, 1-\mathrm{y}, 1 / 2$ $+\mathrm{z}$.

\begin{tabular}{ccccc}
\hline D-H $\cdots \mathrm{A}$ & $\mathrm{D}-\mathrm{H}$ & $\mathrm{H} \cdots \mathrm{A}$ & $\mathrm{D} \cdots \mathrm{A}$ & $\mathrm{D}-\mathrm{H} \cdots \mathrm{A}$ \\
\hline O1-H1A $\cdots \mathrm{O}^{\mathrm{c}}$ & 0.9001 & 2.1185 & 2.9499 & 153.20 \\
O4-H4A $\cdots \mathrm{O}^{\mathrm{h}}$ & 0.9000 & 1.8863 & 2.7242 & 154.06 \\
O4-H4B $\cdots \mathrm{O} 10^{\mathrm{k}}$ & 0.9000 & 1.9792 & 2.8250 & 155.97 \\
O5-H5A $\cdots \mathrm{O}^{\mathrm{c}}$ & 0.9000 & 2.1384 & 2.9499 & 149.58 \\
O7-H7A $\cdots \mathrm{O}^{1}$ & 0.9000 & 2.1145 & 2.7522 & 127.05 \\
\hline
\end{tabular}

